\title{
LOS LUGARES DE MEMORIA EN LA CIUDAD DE MADRID
}

\author{
THE SITES OF MEMORY IN THE CITY OF MADRID
}

\author{
Lucía Soledad Escalante*
}

RESUMEN: La investigación propuesta indagó las relaciones que existen entre el derecho a la memoria y el derecho a la ciudad. Para ello se analizaron desde una teoría crítica de los derechos humanos y teniendo como punto de contacto entre ambos derechos las inscripciones espaciales que materializan la memoria colectiva en la ciudad de Madrid. Es así que se buscó comprobar, desde una dimensión jurídica basada en un enfoque de derechos y con perspectiva espacial, si aquellos lugares que materializan y garantizan la memoria pueden a su vez garantizar el acceso al derecho a la ciudad en virtud de que colaboran en la creación de una ciudad más democrática. La metodología empleada consistió en un análisis crítico de textos, relevamiento y estudio exhaustivo de las normas y estándares nacionales e internacionales, políticas públicas locales, observación y registro de los lugares y, por último, una entrevista en profundidad mediante la técnica de muestra de caso sumamente importante para el problema analizado.

ABSTRACT: The proposed research inquired into the existent ties between the right to memory and the right to the city. For this purpose, those rights were analyzed from a critical theory of human rights and having, as a point of contact between both rights, the spatial inscriptions that materialize the collective memory in the city of Madrid. The investigation sought if those sites that materialize and guarantee memory could also guarantee the access to the right to the city. The methodology used consisted of a critical analysis of texts, an exhaustive survey and study of national and international norms and standards, local public policies, observation and registration of said sites and, finally, an in-depth interview using the case sample technique which is extremely important to the analyzed problem.

PALABRAS CLAVE: Derechos humanos, memoria, ciudad, lugares, espacio.

KEYWORDS: Human rights, memory, city, sites, space.

Fecha de recepción: 07/02/2021

Fecha de aceptación: 29/03/2021

doi: https://doi.org/10.20318/universitas.2021.6193

* Abogada. Becaria de Doctorado del Consejo Interuniversitario Nacional, Programa
PERHID. Docente de la asignatura de Derecho Político de la Facultad de Derecho e
integrante del grupo de Investigación Pensamiento Crítico del Centro de Investigación
en Docencia y Derechos Humanos (CIDDH) "Alicia Moreau" (Universidad Nacional de
Mar de Plata). El presente trabajo se realizó en el marco de la estancia de
investigación doctoral financiada con beca de Fundación Carolina- SEGIB, entre el 04
de noviembre de 2020 y el 29 de enero de 2021 , en el Instituto de Derechos Humanos
Gregorio Peces-Barba de la UC3M y bajo la dirección del Dr. Javier Dorado. E-mail:
lucia escalante@hotmail.com 


\section{1.- INTRODUCCIÓN}

La investigación propuesta indagó, tomando a Madrid como caso de estudio, las relaciones que existen entre el derecho a la memoria y el derecho a la ciudad mediante el análisis de las inscripciones territoriales de la memoria.

Para ello se analizaron el derecho a la memoria y el derecho a la ciudad desde una teoría crítica de los derechos humanos. La teoría crítica, que surge con los aportes de la Escuela de Frankfurt y en la tradición del pensamiento de Marx, tiene como punto de partida la convicción de que es posible transformar las condiciones sociales de opresión y explotación de la realidad, en tanto son construcciones históricas y por ende también susceptibles de ser cambiadas ${ }^{1}$.

En ese sentido, según Herrera Flores una teoría crítica en derechos humanos tiene como punto de partida el "convencimiento de que todo lo que social e individualmente somos está necesariamente sometido a la posibilidad de cambio y transformación" ${ }^{2}$, por lo que desempeña un papel de concienciación que favorece la movilización y mantiene en alto los objetivos y metas trazados en la búsqueda de condiciones de vida digna ${ }^{3}$.

La teoría crítica de los derechos humanos adopta una perspectiva de las víctimas que trata de pensar los derechos humanos y vivirlos desde una opción por las víctimas, en contra de las dinámicas de victimización ${ }^{4}$. Desde esta posición, la memoria se ha convertido en un aspecto decisivo y catalizador para la noción de víctima contemporánea, rescatando una visibilidad de sentido y de interpretación de existencia de su sufrimiento, que permite contribuir a la fundamentación del proyecto y el discurso de los derechos humanos ${ }^{5}$.

Desde mediados del siglo pasado han proliferado los estudios en las ciencias sociales sobre la memoria social ${ }^{6}$, después del hito que

\footnotetext{
1 Theodor Adorno, Epistemología y Ciencias Sociales, (Ediciones Cátedra 2001 [1972]; Horkheimer Max, Teoría crítica (Amorrotu 2003 [1974]).

2 Joaquín Herrera Flores, Los derechos humanos como productos culturales. Crítica del humanismo abstracto (Catarata 2005) 179.

3 Joaquín Herrera Flores, La reinvención de los derechos humanos (Atrapasueños 2008).

${ }^{4}$ Enrique Dussel, Ética de la liberación en la edad de la globalización y de la exclusión (Trotta 2006).

${ }^{5}$ Ariel Arias Marín, 'Teoría crítica y derechos humanos: hacia un concepto crítico de víctima' [2012] 36 Nómadas. Revista Crítica de Ciencias Jurídicas y Sociales <http:redalyc.org/articulo.oa?id=18126450009> acceso 29 Abril 2021.

${ }^{6}$ Maurice Halbwachs fue el primero en acuñar el concepto de memoria colectiva. Su obra "La mémoire collective" se publicó en 1950, como obra póstuma; su idea central es que además del proceso de retención y la memoria individual vinculados con los procesos fisiológicos del cerebro de cada individuo, hay que suponer la existencia de una memoria social que preserva el saber sobre acontecimientos, valores y relaciones dentro de un grupo. Así, el concepto de memoria colectiva permite pensar la memoria y sus objetos en unidades sociales mayores.
} 
marcara el Holocausto, inaugurando un periodo que ha estado signado por asesinatos masivos, masacres y genocidios. La memoria de la Shoah se ha transformado en el modelo de construcción de la memoria a seguir ${ }^{7}$ y funciona como metáfora o paradigma de otras historias traumáticas posteriores ${ }^{8}$. Estos procesos han dejado secuelas en aquellos países que se han visto sometidos por gobiernos autoritarios o que han sufrido períodos de violencia y restricción de las libertades fundamentales, como es el caso de España.

En el marco de la consolidación del Derecho Internacional de los Derechos Humanos y del Derecho Internacional Humanitario a partir de los años 90 del siglo pasado, la comunidad internacional instó a la creación de instrumentos para la lucha contra la impunidad bajo las premisas de verdad, justicia, reparación y memoria, definiendo a esta última como un derecho humano fundamental, y presupuesto para lograr la efectividad de los tres primeros.

Felipe Gómez Isa refiere al derecho a la memoria en su dimensión individual como el derecho a ser recordado a los que se les negó esa posibilidad, pero también como un derecho colectivo de la comunidad de demandar por ese recuerdo de los que ya no existen ${ }^{9}$.

Su importancia recae en una doble dimensión: actúa como reparación de las víctimas y sus familiares evitando el olvido que se traduce en impunidad, y como garantía de no repetición, ya que promueve la creación de una conciencia o memoria colectiva en aquellos países que transitan periodos de justicia transicional; es decir, de cambios políticos que surgen cuando se transita de situaciones de conflicto armado o de regímenes autoritarios hacia la democracia.

En este contexto, la inscripción del recuerdo colectivo en el paisaje urbano es una de las formas para dar cumplimiento al deber de garantizar la recuperación de la memoria que tiene el Estado conforme los estándares internacionales en derechos humanos.

De esta manera, "las marcas territoriales constituyen inscripciones del pasado en el paisaje de la ciudad, y contienen necesariamente cierta materialidad como soporte de memoria"10; se encuentran dentro de lo que Pierre Nora definió como 'lugares de memoria' que invitan a recordar lo allí sucedido, mediante un vínculo topográfico, histórico y social ${ }^{11}$.

Nora ha concebido a los lugares de memoria, ante todo, como restos. Una forma extrema bajo la cual subsiste una conciencia conmemorativa de una historia que solicita a la memoria ante la

\footnotetext{
${ }^{7}$ Annette Wieviorka, L'ère du témoin (Plon 1998).

${ }^{8}$ Andreas Huyssen, En busca del futuro perdido. Cultura y memoria en tiempos de globalización (FCE 2001).

${ }^{9}$ Felipe Gómez Isa (ed), El Derecho a la memoria (Giza Eskubideak 2006).

${ }^{10}$ Cristina Bettanin, 'Territorio marcado: memorias sobre la dictadura en la ciudad de Avellaneda' [2017] Revista de trabajo social 41,43.

${ }^{11}$ Gabriele Dolff Bonekamper, 'Topografías del recuerdo y colectivos de memoria'. en Peter Birle y otros (eds.), Memorias urbanas en diálogo: Berlín y Buenos Aires (buenoslibros 2010).
} 
desritualización del mundo actual, en el que se valoriza "lo nuevo frente a lo antiguo, lo joven frente a lo viejo y el futuro frente al pasado"12.

La relación entre memoria y espacio fue advertida tempranamente por Halbwachs, para quien la mayor parte de los grupos dibujan de alguna manera su forma en el suelo y encuentran sus recuerdos colectivos en un marco espacial definido de esta manera ${ }^{13}$. El espacio es entonces uno de los marcos sociales de la memoria de la comunidad y al igual que el tiempo son construcciones y representaciones colectivas de la identidad de cada grupo.

Los espacios urbanos han sido objeto de estudio mediante las teorías que nacieron en las últimas décadas bajo el impulso de la obra de Henri Lefebvre y sus seguidores. Lefebvre fue quien por primera vez empleó el concepto de derecho a la ciudad, definiéndolo como el derecho de los habitantes urbanos a construir, decidir y crear la ciudad como un espacio privilegiado de lucha anticapitalista ${ }^{14}$. Las teorías urbanas que se enrolan en la tradición lefebvriana tratan de dar respuesta a ciudades cada vez más precarizadas a través de la búsqueda de espacios desde donde promover acciones colectivas de cambio.

El derecho a la ciudad es considerado en la actualidad como un derecho humano por distintos textos 'políticos', como la Carta Europea de Salvaguarda de los Derechos Humanos en la Ciudad (2000) y la Carta Mundial sobre el Derecho a la Ciudad (2004). Sin embargo, aún no ha logrado un reconocimiento jurídico expreso a través de normas internacionales, es así que se trata de un derecho humano emergente ${ }^{15}$ y su situación jurídica resulta similar al ya mencionado derecho a la memoria.

Si bien las dos corrientes académicas mencionadas anteriormente -investigaciones sobre las teorías del espacio y estudios de la memoriahan sido objeto de numerosos análisis, lo cierto es que son muy escasas las investigaciones que relacionan memoria y ciudad y menos aún a estos como derechos humanos. Los autores marxistas que han intentado desbrozar la desigualdad estructural que organiza las relaciones espaciales no han llegado a pensar en los alcances de la memoria colectiva en el espacio ${ }^{16}$. Borja al estudiar el espacio público

\footnotetext{
12 Pierre Nora, Les lieux de mémoire (Trilce 2008) 24.

13 Maurice Halbwachs, La memoria colectiva (Prensas Universitarias de Zaragoza 1968).

${ }^{14}$ Henri Lefebvre, El derecho a la ciudad (Capitán Swing Libros 2017 [1968]).

${ }^{15}$ Pablo Slavin, 'El Derecho a la Ciudad y la escala internacional: la relación dialéctica entre lo global y lo local' en Mariana Calvento (Comp.), Relaciones Internacionales y Actores Locales: dinámicas, estrategias y políticas en el interior de la Provincia de Buenos Aires (CEIPIL 2020).

${ }^{16}$ Estela Schindel, 'Memorias barriales y derecho a la ciudad: la recuperación de ex CCD como práctica de resistencia y reconstitución del tejido social' [2011] Actas del IV Seminario Internacional Políticas de la Memoria, Ampliación del campo de los derechos humanos
} 
destacó la importancia de la construcción de la memoria democrática en el espacio cotidiano de la ciudadanía, en tanto sirve como test sobre la democracia ${ }^{17}$.

Es así que se incursionó en las relaciones existentes entre el derecho a la memoria y el derecho a la ciudad desde una dimensión jurídica, teniendo como punto de contacto entre ambos derechos las inscripciones espaciales que materializan la memoria colectiva en la ciudad de Madrid. El estudio de caso propuesto tiene como ventaja que permite un conocimiento dependiente del contexto y la experiencia ${ }^{18}$ y se inserta en la creciente importancia de los estudios locales -sin perder de vista la perspectiva global- que permiten un desarrollo dentro de las ciudades respetuoso de los derechos humanos.

De esta manera, se buscó comprobar, desde una dimensión jurídica basada en un enfoque de derechos y con perspectiva espacial, si aquellos lugares que materializan y garantizan la memoria pueden a su vez garantizar el acceso al derecho a la ciudad en virtud de que colaboran en la creación de una ciudad más democrática. La relación entre las políticas de memoria en los procesos de justicia transicional con la democracia sienta sus bases en el deber de memoria que ha sido ampliamente sostenido no sólo desde la sociedad civil sino también en las investigaciones académicas. Se debe recordar para no repetir, sólo recordando y teniendo una política activa en relación con el pasado dictatorial, se puede construir democracia en el presente y hacia un futuro ${ }^{19}$.

En ese sentido, Lefebvre señala que "...el carácter democrático de un régimen se mide por su actitud hacia la ciudad, las 'libertades' urbanas, la realidad urbana, y por consiguiente hacia la segregación"20. El autor establece así un fuerte nexo entre democracia y derecho a la ciudad, siendo las inscripciones espaciales de la memoria colectiva un espacio favorable donde pueden concebirse alternativas de una sociedad más justa y equitativa en términos de Derechos Humanos.

\section{2.- METODOLOGÍA EMPLEADA}

A través del análisis crítico de textos se realizó un relevamiento y estudio exhaustivo de las normas y estándares nacionales e internacionales aplicables al objeto de estudio, así como de la bibliografía pertinente. También se efectuó un estudio de tipo cualitativo; la metodología cualitativa ha dado muestra de ser

\footnotetext{
<http://conti.derhuman.jus.gov.ar/2011/10/mesa_17/schindel_mesa_17.pdf> acceso 29 Abril 2021.

${ }_{17}$ Jordi Borja, Revolución urbana y derechos ciudadanos (Café de las Ciudades 2014).

18 Bent Flyvbjerg, 'Cinco malentendidos acerca de la investigación mediante los estudios de caso' [2004] REIS 63.

${ }^{19}$ Elizabeth Jelin, Los trabajos de la memoria (IEP Instituto de Estudios Peruanos 2012); Elizabeth Jelin, La lucha por el pasado: Cómo construimos la memoria social (Siglo Veintiuno Editores 2017).

${ }^{20}$ Henri Lefebvre, El derecho a la ciudad (Capitán Swing Libros 2017 [1968]) 117.
} 
apropiada para abordar la realidad social, pues permite reflejar lo que la gente cree, dice, siente y hace, como producto del modo en que interpreta su mundo ${ }^{21}$.

Se ha seleccionado un estudio de caso con el fin de lograr un acercamiento a los lugares de memoria de la ciudad de Madrid, a los procesos que configuran la producción espacial de la memoria y su rol en la construcción del derecho a la ciudad.

El estudio de caso se basa en un diseño de investigación orientado al análisis de las relaciones entre muchas propiedades concentradas en una sola unidad, son valiosos por su carácter de estudio denso y pueden constituirse en fuentes conceptuales, categoriales y de bases de datos inherentes a la construcción de una teoría, aunque no es lo que se pretende en principio ${ }^{22}$, sino más bien al recurrir a diseños que combinan diferentes metodologías con preeminencia de los métodos cualitativos tienen como objetivo "la construcción de teoría de diferente alcance y nivel, para interpretar y explicar la vida y organización social"23.

En un primer momento se realizó una investigación histórica con la indagación y recopilación de material bibliográfico y normativo pertinente que permitió definir conceptos y parámetros mediante el análisis de textos. Se efectuó un análisis de los estándares internacionales y nacionales, como así también de las políticas públicas vigentes en relación a las inscripciones territoriales en la ciudad de Madrid. Para ello se tuvo en consideración la Ley española de Memoria Histórica $n^{\circ} 52 / 2007^{24}$ que regula en los artículos 15 y 16 el temperamento que debiera adoptarse en cuanto a los símbolos y monumentos públicos franquistas y en particular el Valle de los Caídos y la labor realizada por el Comisionado de Memoria Histórica del Ayuntamiento de Madrid.

Posteriormente, se pasó a una fase de investigación específica con el relevamiento de casos representativos como lugares de memoria de Madrid, su investigación bibliográfica y registro fotográfico a los fines de corroborar el estado de su reconocimiento y difusión. También se realizó una entrevista en profundidad a una actora social involucrada con la temática y específicamente con uno de los casos representativos que más debates ha suscitado recientemente, el Cementerio del Este o Cementerio de La Almudena, ello con el fin de completar la información recolectada y considerando que es una estrategia para hacer que la gente hable sobre lo que sabe, piensa y cree, una situación

${ }^{21}$ Robert Bogdan y Steven Taylor, Introducción a los Métodos Cualitativos de Investigación (Paidós 1986).

${ }^{22}$ Alberto Marradi, Nélida Archenti y Juan Ignacio Piovani, Metodología de las ciencias sociales (Emecé Editores 2007).

${ }^{23}$ Guillermo Neiman y German Quarante, 'Los estudios de caso en la investigación sociológica', en Irene Vasilachis De Gialdino (Coord.) Estrategias de investigación cualitativa (Editorial Gedisa 2006) 223.

24 Boletín Oficial del Estado, núm. 310 de 27/12/2007 <https://boe.es/eli/es/l/2007/12/26/52/com> acceso 29 Abril 2021. 
en la cual se obtiene información sobre la biografía, sentido de los hechos, sentimientos, opiniones y emociones, las normas o estándares de acción, y los valores o conductas ideales del entrevistado ${ }^{25}$.

\section{3.- DERECHO A LA MEMORIA Y DERECHO A LA CIUDAD}

Tanto el derecho a la memoria como el derecho a la ciudad, las condiciones en las que estos surgen como así también sus objetivos, se enmarcan en la teoría crítica de los derechos humanos que se asume como postulado de esta investigación. Ambos surgen de luchas sociales en busca de la dignidad humana y con un gran potencial emancipador, el primero como reparación a las víctimas de la violación a sus derechos humanos y como garantía de no repetición a la sociedad en su conjunto de los hechos aberrantes del pasado $y$; el segundo que tiende a garantizar el uso y goce de una ciudad más democrática e inclusiva.

En primer lugar, cabe remarcar el carácter amplio e inclusivo del derecho a la ciudad de otros derechos humanos. En ese sentido, no se limita al derecho a las prestaciones básicas en materia de bienestar: vivienda, confort, calidad ambiental, servicios, uso del espacio público y la participación, sino que para Lefebvre es mucho más amplio, refiere al derecho a la vida urbana, a la centralidad renovada, a los lugares de encuentros y de intercambios, a los ritmos de vida y empleos del tiempo que permiten el uso pleno y entero de estos momentos y lugares ${ }^{26}$.

Borja describe la amplitud de este derecho y refiere que integra derechos relativos tanto al entorno físico (vivienda, el espacio público, transporte, ambiente, etc.) pero también aquellos derechos políticos y sociales que a su vez condicionan la inserción en la ciudad de las minorías 27.

En este contexto es que encontramos la primera relación entre el derecho a la ciudad y el derecho a la memoria en la Carta Mundial del año 2004, el artículo punto 1 establece que "Todas las personas tienen derecho a la ciudad sin discriminaciones de género, edad, raza, etnia u orientación política y religiosa. Junto con esto, se debe preservar la memoria y la identidad cultural en conformidad con los principios y normas que se establecen en esta Carta"28.

A lo largo del texto se le da contenido al derecho a la ciudad, sosteniendo en el punto 2 del artículo 1 que "es interdependiente de todos los derechos humanos internacionalmente reconocidos, concebidos integralmente, e incluye, por tanto, todos los derechos

\footnotetext{
${ }^{25}$ Rosana Guber, La etnografía. Método, campo y reflexividad (Editorial Norma 2001).

${ }^{26}$ Henri Lefebvre, El derecho a la ciudad (Capitán Swing Libros 2017 [1968]).

27 Jordi Borja, Revolución urbana y derechos ciudadanos (Editorial Café de las Ciudades 2014).

28 Carta Mundial del Derecho a la Ciudad del año 2004 <https://www.right2city.org/wp-content/uploads/2019/09/A1.1 Carta-Mundial-deDerecho-a-la-Ciudad.pdf > acceso 29 Abril 2021.
} 
civiles, políticos, económicos, sociales, culturales y ambientales que ya están reglamentados en los tratados internacionales de derechos humanos".

Lo dispuesto destaca la relación entre el acceso al derecho a la ciudad de todas las personas y la importancia de preservar la memoria y la identidad del grupo en tanto constituyen derechos humanos, por lo que son interdependientes y es necesario concebirlos integralmente. Además, la relación que existe entre memoria e identidad y que surge en la Carta es de mutua constitución en la subjetividad de los individuos que viven en un determinado grupo y que cualquier construcción de esta última está ligado a un sentido de permanencia a los largo del tiempo y el espacio, poder recordar algo es lo que sostiene a la identidad ${ }^{29}$.

Ahora bien, Karen Till partiendo de los conceptos de Lefebvre y a través de estudios etnográficos realizados en diferentes comunidades argumenta sobre la necesaria relación que existe entre la memoria y el derecho a la ciudad. La autora a través de diferentes ejemplos describe cómo ciertos cuidados y atenciones del lugar y sus habitantes son prácticas éticas y políticas significativas que pueden funcionar para constituir reinos urbanos más democráticos.

En ese sentido argumenta que "llama la atención la importancia del arte, la memoria y la imaginación en la comprensión y creación de una ciudad más justa. El trabajo de memoria y las prácticas creativas de estos residentes desplazados ofrecen importantes lecciones sobre reteorizar la ciudad y pensar de manera diferente las posibilidades de políticas urbanas" 30 .

Till siguiendo al sociólogo francés entiende a la ciudad como una obra construida por sus habitantes que producen el espacio, pero las define como 'heridas' ya que han sido dañadas y estructuradas en contextos históricos de destrucción, desplazamiento y trauma tanto individual como social que fue resultado de la violencia ejercida por el Estado. Esta concepción de las ciudades impide que el espacio urbano sea entendido solo como propiedad, ya que si las ciudades y sus habitantes fueron heridos por el Estado y las prácticas sociopolíticas dominantes, estos tienen el derecho de repensar otros futuros posibles más justos a través de los trabajos de memoria que realizan en el lugar mediante diversos recursos históricos y actuales.

Este concepto de 'ciudades heridas' de la autora nos interesa especialmente porque hace evidente la necesaria recuperación de la memoria en la ciudad. Retomando el concepto acuñado por Lefebvre de derecho a la ciudad, se ha reconocido como los estados democráticos suelen negar a sus habitantes el acceso equitativo a los

${ }^{29}$ Elizabeth Jelin, Los trabajos de la memoria (IEP Instituto de Estudios Peruanos 2012).

${ }^{30}$ La traducción de la cita del inglés al castellano es propia.

Karen Till, 'Wounded cities: Memory-work and a place-based ethics of care' [2012] 31 Revista Political Geography 1, 5. 
recursos de la ciudad, incluyendo vivienda, espacio público, libertad de expresión, participación y, también el derecho a narrar el pasado a través de medios legales y materiales. Es así que, "este derecho a representar el pasado, puede considerarse entonces como parte del derecho a la ciudad y, por ende está íntimamente ligado a los procesos de democratización"31. La memoria del pasado en los entornos urbanos sostienen posibilidades de futuros diferentes ${ }^{32} \mathrm{y}$, es recordando mediante políticas activas en relación con el pasado dictatorial que se puede construir democracia en el presente y hacia un futuro ${ }^{33}$.

El recuerdo se inscribe en el espacio público de las ciudades para su visibilización y accesibilidad por parte de todos. Lefebvre no desarrolló en profundidad el concepto de espacio público, probablemente porque este concepto tomó relevancia en el ámbito académico décadas después. En su obra 'La producción del espacio' lo distingue del espacio privado en tanto el primero -el espacio comunitario- es dominado, mientras que el segundo -el espacio interno de la vida familiar- es apropiado $y$, aunque se distinguen no llegan a su disociación, pueden ir juntos y sostiene que debería evitarse su separación absoluta para evitar su contradicción ${ }^{34}$.

Borja -retomando las ideas de Lefebvre- estudió al espacio público tanto en su aspecto físico como también en su sentido político cultural y argumentó que este "puede servir de test sobre la democracia, su cualidad y sus déficits" 35 , o bien su negación, como en el caso de los regímenes autoritarios. De esta manera, realza la importancia de la construcción de la memoria democrática ${ }^{36}$ en el espacio público.

La ciudad democrática por regla está constituido por espacio público que engloba el conjunto de la vida social e institucional, contiene la historia, condensa el pasado y la memoria, produciendo proyectos de futuro que dan sentido al presente a través de un patrimonio colectivo que combina lugares físicos con recuerdos, sentimientos y momentos comunitarios ${ }^{37}$. En ese sentido, Kuri Pineda encuentra como elementos comunes entre el espacio público y la memoria que ambos se definen por la heterogeneidad social, cultural

\footnotetext{
${ }^{31}$ La traducción de la cita del inglés al castellano es propia.

Karen Till, 'Wounded cities: Memory-work and a place-based ethics of care' [2012] 31 Revista Political Geography 1, 8.

32 David Harvey, Justicia, naturaleza y geografía de la diferencia (Traficantes de sueños 2018 [1996]).

${ }^{33}$ Elizabeth Jelin, Los trabajos de la memoria (IEP Instituto de Estudios Peruanos 2012); Elizabeth Jelin, La lucha por el pasado: Cómo construimos la memoria social (Siglo Veintiuno Editores 2017).

${ }^{34}$ Henri Lefebvre, La producción del espacio (Capitán Swing Libros 2013 [1974]).

35 Jordi Borja, Revolución urbana y derechos ciudadanos (Editorial Café de las Ciudades 2014) 180.

${ }^{36}$ Borja define a la memoria democrática como aquella que significa el reconocimiento y la difusión de las múltiples formas de resistencia social y cultural, la lucha democrática y de rechazo de la dictadura -haciendo referencia al franquismo- que fueron determinantes para evitar su continuidad durante la transición.

37 Jordi Borja, Espacio público, ciudad y ciudadanía (Electa 2001).
} 
y política, son objeto de disputa, cuentan con un claro revestimiento simbólico y un nexo estrecho con la identidad, siendo arena de lucha política y social en aras de edificar hegemonía y legitimidad ${ }^{38}$.

En las épocas de transición, las políticas públicas de memoria en relación al espacio público se basan no sólo en suprimir la exaltación de símbolos relacionados con el terrorismo de Estado sino también en reconocimientos de la responsabilidad estatal, homenaje a las víctimas y todas aquellas relacionadas con el sustento de valores democráticos y de respeto a los derechos humanos.

\section{4.- LA MEMORIA Y SUS LUGARES EN LA CIUDAD DE MADRID}

Ante la amplitud del concepto 'lugares de memoria' de Pierre Nora que refiere tanto a unidades significativas de orden material 0 simbólico, dejando de lado conceptualmente una perspectiva exclusivamente espacial, es que se prefiere hacer referencia a las marcas en la superficie urbana que a su vez, están contenidas en la categoría más amplia que desarrollara el historiador francés, como 'inscripciones espaciales de la memoria' en términos de Schindel ${ }^{39}$. Desde una geografía de la memoria no sólo se estudian los sitios materiales sino también expresiones ceremoniales y prácticas performativas ${ }^{40}$, por lo que las 'inscripciones espaciales de la memoria' engloban un amplio espectro de casos.

Desde este nuevo enfoque en que Les lieux de mémoire de Nora permiten integrar la consideración de las cuestiones espaciales en la historiografía de los símbolos y la construcción de las identidades territoriales es que se refiere a las 'inscripciones espaciales de la memoria' como aquellas en las que los grupos tienden a fijar el pasado en el espacio no como simples marcas fijas, sino que están en constante elaboración, son resignificadas y reinterpretadas.

El discurso que logra instalarse junto con la marca territorial siempre tiene un sentido político, público y colectivo específico, en él puede advertirse la dinámica de las relaciones de poder que organiza el proceso de producción espacial de la memoria. Su instalación es siempre el resultado de luchas y conflicto, como así también su existencia es un recordatorio de un pasado conflictivo que puede a la

\footnotetext{
${ }^{38}$ Edith Kuri Pineda, 'La construcción social de la memoria en el espacio: una aproximación sociológica' [2017] 11 Revista Península 9.

${ }^{39}$ Estela Schindel, 'Memorias barriales y derecho a la ciudad: la recuperación de ex CCD como práctica de resistencia y reconstitución del tejido social' [2011] Actas del IV Seminario Internacional Políticas de la Memoria, Ampliación del campo de los derechos humanos

<http://conti.derhuman.jus.gov.ar/2011/10/mesa_17/schindel_mesa_17.pdf> acceso 29 Abril 2021.

40 Joaquín García Álvarez, 'Lugares, paisajes y políticas de memoria: una lectura geográfica' [2009] Boletín de la A.G.E. 175.
} 
vez disparar nuevos debates sobre el sentido del pasado que se le da en los distintos periodos y por diferentes generaciones ${ }^{41}$.

En el sistema universal de protección de los Derechos Humanos, la Comisión de Derechos Humanos de la ONU promulgó los 'Principios contra la impunidad', a través del informe del relator especial Luis Joinet de 1997 (E/CN.4/Sub.2/1997/20/Rev.1) ${ }^{42}$, en el que se tipificaron los derechos a la verdad, la justicia y la reparación, haciendo énfasis en el derecho a la memoria como presupuesto para la efectividad de los tres primeros.

Estos principios fueron actualizados en el año 2005 por la experta independiente Diane Orentlicher (E/CN.4/2005/102/Add.1) ${ }^{43}$ y su estructura se divide en tres secciones: el derecho de las víctimas a saber, el derecho de las víctimas a la justicia y el derecho a obtener reparación. Además, suma a título preventivo una serie de medidas destinadas a garantizar la no reiteración de las violaciones.

En primer lugar, se les reconoce a las víctimas y sus familiares el derecho inalienable a la verdad acerca de las circunstancias en que se cometieron las violaciones $y$, en caso de fallecimiento o desaparición, sobre la suerte que corrió la víctima (principios $n^{\circ} 3$ conforme la redacción original y $n^{\circ} 4$ del texto actualizado).

Pero este derecho no sólo pertenece a las víctimas directas e indirectas sino a toda la sociedad generando como contrapartida el deber de recordar y el derecho a la memoria en su dimensión colectiva. En este sentido, establece que cada pueblo tiene el derecho inalienable a conocer la verdad acerca de los acontecimientos sucedidos y las circunstancias y los motivos que llevaron, mediante la violación masiva y sistemática de los derechos humanos, a la perpetración de crímenes aberrantes. Concluye que el ejercicio pleno y efectivo del derecho a la verdad es esencial para evitar que en el futuro se repitan las violaciones (principio no 1 conforme E/CN.4/Sub.2/1997/20/Rev.1 y principio $\mathrm{n}^{\circ} 2$ de E/CN.4/2005/102/Add.1).

En segundo lugar, recepta el derecho a la justicia que conlleva como deberes del Estado realizar investigaciones rápidas, minuciosas, independientes e imparciales y adoptar las medidas apropiadas respecto de sus autores, especialmente en la esfera de la justicia penal, para que sean procesados, juzgados y condenados debidamente. En los procesos judiciales se les reconoce amplia participación jurídica a las víctimas, sus familiares y a toda persona u organización no gubernamental que tenga un interés legítimo, junto con la posibilidad de hacer valer sus derechos beneficiándose de un recurso equitativo y

\footnotetext{
${ }^{41}$ Elizabeth Jelin, La lucha por el pasado: Cómo construimos la memoria social (Siglo Veintiuno Editores 2017).

${ }^{42}$ Informe Final de la Comisión de Derechos Humanos, Naciones Unidas.

<https://undocs.org/es/E/CN.4/Sub.2/1997/20/Rev.1> acceso 29 Abril 2021.

${ }_{43}$ Informe en la Oficina del Alto Comisionado para los Derechos Humanos, Naciones Unidas

<https://ap.ohchr.org/documents/dpage s.aspx?si=E/cn.4/2005/102/Add.1> acceso 29 Abril 2021.
} 
efectivo que permita lograr que su opresor sea juzgado y obtener reparación (principios $\mathrm{n}^{\circ} \quad 18$ del documento E/CN.4/Sub.2/1997/20/Rev.1 y n 19 del E/CN.4/2005/102/Add.1).

Por último, conforme los principios elaborados en torno al derecho a obtener reparación, ésta deberá abarcar todos los daños y perjuicios sufridos por las víctimas, comprendiendo las medidas de restitución, indemnización, rehabilitación y satisfacción según lo establece el derecho internacional (principios $\mathrm{n}^{\circ} 36$ y 34 de los documentos E/CN.4/Sub.2/1997/20/Rev.1 y E/CN.4/2005/102/Add.1).

En su informe especial, el relator Joinet retomó la 'Estructura de principios y directivas fundamentales concernientes al derecho a reparación de las víctimas de violaciones flagrantes de los derechos humanos y del derecho humanitario' establecidos por $M$. Theo van Boven (E/CN.4/Sub.2/1996/17) ${ }^{44}$ y, clasificó en tres tipos las medidas comprendidas: a) Medidas de restitución (tendientes a que la víctima pueda volver a la situación anterior a la violación); b) Medidas de indemnización (reparan el perjuicio psíquico y moral, así como la pérdida de una oportunidad, daños materiales, atentados a la reputación y gastos de asistencia jurídica); c) Medidas de readaptación (comprenden atención médica -psicológica y psiquiátrica-). También se hace referencia a las 'medidas de satisfacción', que son enumeradas en el principio $n^{\circ} 15$ de los principios y directrices elaborados por $M$. Theo van Boven y que son caracterizadas como 'garantías de no repetición'.

En este sentido, la Resolución 60/147 aprobada por la Asamblea General en $2005^{45}$ y que recepta los 'Principios y directrices básicos sobre el derecho de las víctimas de violaciones manifiestas de las normas internacionales de derechos humanos y de violaciones graves al derecho internacional humanitario a interponer recursos y obtener reparaciones', establece en los principios 18 a 23 que se debe dar a las víctimas, de forma apropiada y proporcional a la gravedad de la violación a sus derechos humanos sufrida y a las circunstancias de cada caso, una reparación plena y efectiva, en forma de restitución, indemnización, rehabilitación, satisfacción y/o garantías de no repetición. Las tres primeras formas están dirigidas exclusivamente a las víctimas directas, mientras que las últimas dos al incluir el conocimiento de la verdad, su difusión pública, pedido de disculpas, conmemoraciones, la educación y promoción en derechos humanos, entre otras, se orientan e impactan también en el resto de la sociedad.

De esta manera, las medidas de reparación actúan en el plano individual de las víctimas como un resarcimiento que debe ser integral,

44 Documento de la Comisión de Derechos Humanos, Naciones Unidas $<$ https://documents-dds-

ny.un.org/doc/UNDOC/GEN/G96/128/33/PDF/G9612833.pdf?OpenElement> acceso 29 Abril 2021.

45 Resolución de la Asamblea General de Naciones Unidas 60/147 $<$ https://www.ohchr.org/sp/professionalinterest/pages/remedyandreparation.aspx

$>$ acceso 29 Abril 2021. 
beneficiándose de un recurso eficaz y con procedimientos públicos aplicables. Pero también, aquellas de carácter simbólico tienen incidencia a nivel colectivo, como el reconocimiento público hecho por el Estado de su responsabilidad, las declaraciones oficiales de restablecimiento de la dignidad de las víctimas, los actos conmemorativos, los bautizos de vías públicas, las erecciones de monumentos y la inclusión de la enseñanza de los hechos ocurridos en los distintos niveles educativos, que facilitan el deber de recordar al grupo y las cuales son objeto de esta investigación.

Ahora bien, en el sistema regional y a diferencia de lo que ocurre en el Sistema Interamericano de Derechos Humanos ${ }^{46}$ que sigue los lineamientos generales de los 'Principios contra la impunidad', el Tribunal Europeo de Derechos Humanos (TEDH) no ha referido expresamente a la memoria y menos aún a la necesidad de reconocer a las víctimas en el espacio público mediante inscripciones en su reconocimiento o bien, a través de la recuperación, señalización y refuncionalización de aquellos lugares que resultan emblemáticos de las violaciones a sus derechos humanos.

En cuanto a las reclamaciones de satisfacción equitativa receptadas en el art. 41 del Convenio Europeo de Derechos Humanos (CEDH) para aquellos casos en que la normativa interna repara de manera imperfecta la violación de un Estado parte de sus obligaciones respecto al Convenio, las medidas acordadas por el Tribunal se presentan normalmente en forma de concesión de una suma monetaria a la parte perjudicada que incluye indemnizaciones pecuniarias por daños materiales, daños morales, el pago por las costas del proceso y los gastos de abogados, por lo que deja de lado aquellas de tipo simbólico que exceden la dimensión individual extendiéndose a la comunidad en su conjunto 47 .

Por otra parte, en cuando al derecho a la verdad sólo reconoce su dimensión individual y para casos de violaciones actuales a los derechos humanos, no así de aquellas referidas a cuestiones de justicia

\footnotetext{
${ }^{46}$ La Corte Interamericana de Derechos Humanos hace referencia de forma expresa en sus sentencias a la memoria, pero sin dar pautas claras a las obligaciones que de ella emanan y siempre en relación con los otros tres pilares de la justicia transicional: verdad, justicia y reparación. Ha profundizado en mayor medida en la memoria como "consecuencia" de la reparación. En el caso 'Aloeboetoe y otros vs. Surinam' del año 1991 incluyó medidas de satisfacción que consideran también a la sociedad en la que se generó el daño. Entre las medidas de reparación ordenadas por la Corte encontramos numerosas con incidencia en el espacio público como aquellas que implican renombrar establecimientos, calles y colocar placas en reconocimiento a las víctimas (Caso los 19 Comerciantes vs. Colombia; Caso Niños de la Calle (Villagran Morales y Otros) vs. Guatemala; Baldeón García vs. Perú; 'la Masacre Ituango vs. Colombia, entre otros) y también la obligación de construir monumentos o memoriales (Caso Masacre Plan Sánchez vs. Guatemala, Sent. 19 Noviembre 2004, párr. 23). El análisis en profundidad de su jurisprudencia excede el objeto de la investigación que estudia particularmente el caso español.

${ }^{47}$ Luis Cruz, 'La reparación de las víctimas en el Convenio Europeo de Derechos Humanos' [2010] 12 Revista Española de Derecho Internacional 89.
} 
transicional. Sin perjuicio de ello, López Guerra releva una serie de casos en el último tiempo, en los que se ha reconocido una mayor amplitud de este derecho, aunque como reforzamiento del derecho de las víctimas sin una dimensión autónoma. El Tribunal ha preferido, sin ignorar la dimensión colectiva del derecho a la verdad, limitar sus efectos a la existencia de una investigación adecuada de los hechos destinada a remediar en lo posible la violación producida y el daño causado a las víctimas. Es posible encontrar una alternativa a la dimensión colectiva desde la perspectiva del art. 10 del Convenio, relativo al derecho a recibir o impartir informaciones, en el que se tiene en cuenta el interés del público aunque de modo indirecto y está condicionado por aquello documentado expresamente por el Estado ${ }^{48}$.

En el ámbito interno se sancionó la Ley de Memoria Histórica nº $52 / 2007$ que en su exposición de motivos reconoce un derecho individual a la memoria personal y familiar de cada ciudadano (art. 2) pero sin hacer referencia a la vertiente colectiva. Es más, en el último párrafo refiere que no es tarea del legislador implantar una determinada memoria colectiva, pero sí reparar a las víctimas y sus familiares conforme los valores democráticos. Pese a ello, establece una serie de medidas en relación con los símbolos y monumentos conmemorativos, sustentadas en el principio de evitar toda exaltación de la sublevación militar, de la Guerra Civil y de la represión de la Dictadura, con el convencimiento de que los ciudadanos tienen derecho a que los símbolos públicos sean ocasión de encuentro y no de enfrentamiento, ofensa o agravio (arts. 15 y 16).

El artículo 15 hace referencia a la potestad de las administraciones públicas de tomar medidas oportunas para retirar todos aquellos "escudos, insignias, placas y otros objetos 0 menciones conmemorativas de exaltación, personal o colectiva, de la sublevación militar, de la Guerra Civil y de la represión de la Dictadura". Agrega que se pueden incluir entre estas medidas la retirada de subvenciones o ayudas públicas, no siendo aplicable cuando las menciones sean de estricto recuerdo privado sin exaltación o bien, cuando concurran razones artísticas, arquitectónicas o artístico-religiosas protegidas por la ley. Lo dispuesto por la ley presenta como déficit que no establece ninguna sanción para los casos en los que no se proceda a retirar símbolos franquistas por lo que ha presentado dificultades en su cumplimiento.

El artículo 16 regula específicamente el caso del Valle de los Caídos estableciendo que se regirá estrictamente por las normas aplicables con carácter general a los lugares de culto y a los cementerios públicos, estando prohibido en el recinto los actos de naturaleza política y exaltadores de la Guerra Civil, de sus protagonistas, o del franquismo. El punto 3 fue agregado por el Real Decreto-ley 10/2018 y establece

\footnotetext{
${ }^{48}$ Luis López Guerra, 'El derecho a la verdad: ¿la emergencia de un nuevo derecho en la jurisprudencia del Tribunal Europeo de Derechos Humanos?' [2018] 22 Anuario Iberoamericano de Justicia Constitucional 11.
} 
que sólo podrán yacer los restos mortales de personas fallecidas a consecuencia de la Guerra Civil española, como lugar de conmemoración, recuerdo y homenaje a las víctimas de la contienda 49 .

De esta manera, si bien el texto legal hace referencia a la supresión de determinados símbolos y monumentos del espacio público como así también al temperamento a adoptar respecto del Valle de los Caídos, lo cierto es que no propone la recuperación de ciertos lugares emblemáticos y constitutivos de la memoria colectiva y tampoco refiere a la colocación de cualquier tipo de conmemoración de las víctimas como reparación, reconocimiento e inscripción espacial de su recuerdo que pertenece y constituye la identidad de toda la comunidad ${ }^{50}$.

En el ámbito local, el Ayuntamiento de Madrid para dar cumplimiento a lo normado por la Ley n 52/2007 creó en el año 2016 el Comisionado de la Memoria Histórica, asumiendo como postulado que "la preservación de la memoria histórica de una ciudad es una expresión de su libertad y de que la reivindicación del compromiso político de la ciudadanía en la conquista de las libertades es una manifestación de cultura democrática"51. Por lo que reconoce la importancia de la memoria en la ciudad como expresión de las conquistas democráticas en el espacio público en concordancia con los desarrollos teóricos que fueran propuestos y que interrelacionan ambos derechos humanos: el derecho a la memoria y el derecho a la ciudad.

\footnotetext{
${ }^{49}$ Mediante esta disposición se pudo llevar acabo la exhumación de Francisco Franco el pasado 26 de diciembre de 2019, luego de que el Tribunal Supremo la avalara pese al recurso interpuesto por la familia para evitarlo.

${ }^{50}$ El reciente anteproyecto de Ley de Memoria Democrática significaría un notorio avance en este sentido al ampliar en el artículo 1 su objeto y finalidad a la promoción de la reparación moral y de la recuperación de la memoria colectiva. De esta manera, declara buscar "la recuperación, salvaguarda y difusión de la memoria democrática, como conocimiento de la reivindicación y defensa de los valores democráticos y los derechos y libertades fundamentales", fomentando "la cohesión y solidaridad entre las diversas generaciones en torno a los principios, valores y libertades constitucionales".

En concordancia, con el reconocimiento a la dimensión colectiva del derecho a la memoria es que en el Capítulo IV hace hincapié en ésta como deber y garantía de no repetición, receptando en cuatro secciones distintas medidas tendientes a evitar que las violaciones a los derechos humanos puedan volver a repetirse, incluyendo una dedicada a los lugares de memoria democrática.

Los lugares de memoria democrática son conceptualizados en el artículo 50 de una forma amplia, incluyendo todos aquellos bienes materiales o inmateriales que de algún u otro modo están "vinculados a la memoria democrática, la lucha de la ciudadanía española por sus derechos y libertades, la memoria de las mujeres, así como con la represión y violencia sobre la población como consecuencia de la resistencia al golpe de Estado de julio de 1936, la Guerra Civil, la Dictadura, el exilio y la lucha por la recuperación y profundización de los valores democráticos".

${ }^{51}$ Informe Propuesta del Comisionado de Memoria Histórica sobre Revisión del

Callejero del Ayuntamiento de Madrid, p. 1

$<$ https://www.madrid.es/UnidadesDescentralizadas/UDCPleno/CentroDocumentacio n/DocComisionado/2\%20Informe Propuesta Comisionado Revisi\%C3\%B3n.pdf> acceso 29 Abril 2021.
} 
Su accionar se enmarca en la línea recogida por el Plan Estratégico de Derechos Humanos del Ayuntamiento de Madrid 2017-201952. Ante las limitadas políticas municipales para la contribución al derecho a la verdad, la justicia y la reparación de las víctimas de graves violaciones de derechos humanos, de acuerdo a la normativa estatal y los estándares y recomendaciones internacionales, propuso en su Meta 5 objetos y acciones tendientes a garantizar el Derecho a la verdad, justicia y reparación.

Es así que con el fin de cumplir con la normativa nacional vigente sobre derechos de las víctimas, así como las recomendaciones de los mecanismos internacionales de derechos humanos también en relación con los derechos de las víctimas de violaciones graves del derecho internacional de los derechos humanos, en especial las relacionadas con las víctimas de la Guerra Civil y el franquismo, propuso adoptar diferentes medidas para garantizar el cumplimento efectivo de la Ley Orgánica 52/2007.

Entre las líneas de acción asumidas encontramos aquella que hace referencia a la creación, recuperación y/o resignificación de determinados espacios como Lugares de Memoria especialmente significativos (fosas, lugares de represión y privación de libertad, prisiones, cementerios). Luego de su localización, se buscará contribuir a su contextualización adecuada y a ampliar las distintas narraciones de la ciudad y el reconocimiento público de todas las víctimas sin discriminación (en especial, las víctimas del franquismo). También se adoptarán medidas concretas para la adecuada conservación de espacios o lugares de la memoria ya existentes. Todo ello con la colaboración de las asociaciones de víctimas, del conocimiento de la ciudadanía sobre esos Lugares de Memoria y sobre la Memoria de las violaciones graves del derecho internacional de los derechos humanos, con independencia de quienes hayan sido los perpetradores $y$, a través de los espacios culturales municipales.

El Plan Estratégico contribuye entonces con sus metas, objetivos estratégicos y líneas de acción en la búsqueda de una ciudad respetuosa de los derechos humanos en un sentido amplio, contribuyendo así al goce del derecho a la ciudad y específicamente a la memoria conforme lo receptado en la Sección 2, Meta 5.

Ahora bien, el Comisionado de la Memoria Histórica actuó como órgano colegiado de asesoramiento y propuesta de las actuaciones municipales de cumplimiento de la Ley $n^{\circ}$ 52/2007 hasta su disolución en el año 2018, entre sus funciones se encontraba: "Elaborar, por iniciativa propia, informes y recomendaciones sobre la política de Memoria Histórica del Ayuntamiento de Madrid" (art. 4 inc. h del Acuerdo por el que se creó el Comisionado de la Memoria Histórica del Ayuntamiento de Madrid).

52 Plan Estratégico en Derechos Humanos del Ayuntamiento de Madrid (20172019)<https://www.madrid.es/UnidadWeb/Contenidos/Descriptivos/ficheros/PlanD DHH Madrid.pdf> acceso 29 Abril 2021. 
Entre las medidas para el cumplimiento de su finalidad en el espacio público de la ciudad confeccionó un plan de modificación del Callejero de la ciudad, habiéndose relevado luego de realizarse una amplia consulta a las Juntas Municipales de los Distritos un total de 53 (vías públicas y espacios urbanos) calles, plazas, avenidas y paseos cuyo nombre debía ser cambiado en virtud de lo normado en el art. 15. La propuesta fue impugnada en algunos de los casos por vía judicial por lo que no se logró efectivizar.

Por otra parte, también elaboró una propuesta para reconocer a personajes, colectivos e instituciones cuya trayectoria fue relevante en asuntos relacionados con la memoria histórica de la ciudad de Madrid mediante la colocación de placas en lugares que, por uno u otro motivo, estuvieran conectados con los homenajeados.

Ahora bien, interesa especialmente a la investigación lo propuesto por el Comisionado en relación a la conveniencia de crear espacios de Memoria en las cárceles, cementerios y otros lugares importantes para la recuperación de la memoria en la ciudad. En esa línea, declaró como objetivo de la política pública de memoria propuesta: "asumir como patrimonio de la sociedad, los esfuerzos, conflictos, luchas y memorias que han hecho posible el mantenimiento de los valores que vertebran las pautas de convivencia democráticas de la sociedad que nosotros mismos hemos construido", agregando que "el espacio físico se debe erigir como un elemento imprescindible de recuerdo pues es en él, donde se materializan esas vulneraciones de derechos" 53 .

Se elaboró un catálogo representativo de Lugares de Memoria en Madrid, recuperando el término de Pierre Nora y aludiendo con este a "cualquier realidad significativa -material o inmaterial- susceptible de convertirse en un elemento simbólico del pasado de una determinada comunidad". Estos lugares son clasificados en dos tipos: "los negativos (cementerios, cárceles o checas), lugares de sufrimiento y represión política injusta y violación de derechos y libertades políticas, religiosas, etc.; y los positivos, (colegios, instituciones, embajadas, etc.), vinculados a la educación, la salud pública, la tolerancia, la libertad y la cultura"54. También agrega otros lugares relacionados a acontecimientos y personajes cuya trayectoria sea acreedora de recuerdo.

Cabe hacer mención que si bien los lugares de memoria recogidos por el informe incorporan espacios donde ocurrieron hechos que significaron violaciones a los derechos humanos perpetrados tanto por

\footnotetext{
${ }^{53}$ Acta del Comisionado de la Memoria Histórica del Ayuntamiento de Madrid, Sesión (7/2016) ordinaria de 28 de octubre de 2016, p. 5 $<$ https://www.madrid.es/UnidadesDescentralizadas/UDCPleno/CentroDocumentacio n/DocComisionado/21\%20Actas Comisionado 2016.pdf> acceso 29 Abril 2021.

${ }^{54}$ Informe propuesta del Comisionado de Memoria Histórica sobre creación de Lugares de Memoria en la ciudad de Madrid, p. 4

<https://www.madrid.es/UnidadWeb/Contenidos/Navegaciones/Memoria Historica/ Memoria HIstorica/InformesFicheros/InformeLugaresMemoria.pdf > acceso 29 Abril 2021.
} 
el régimen autoritario instaurado luego de la Guerra Civil como también durante ésta por las autoridades de un gobierno electo legítimamente, se comparte el criterio de Borja al entender que la memoria democrática debería implicar especialmente "analizar y denunciar el carácter perverso de la dictadura franquista (...) significa el reconocimiento y la difusión de las múltiples formas de resistencia social y cultural, la lucha democrática y de rechazo de la dictadura que fueron determinantes para evitar su continuidad durante la transición"55.

El informe incluye las intervenciones que se proponen en dichos lugares pero sin realizar ningún tipo de explicación de sus alcances e implicancias, estas son: identificación externa con señalización diseñada al efecto; carácter pedagógico; protagonismo de las víctimas; ensalzamiento de valores de paz y concordia y; empleo de nuevas tecnologías cuando sea posible.

A los fines de corroborar el cumplimiento de lo propuesto y el avance en la consolidación de los valores democráticos en el espacio público, tal como fuera el objetivo general del Comisionado alineado con lo dispuesto por la Ley 52/2007, es que se realizó observación y registro fotográfico entre los días 07 de noviembre y 05 de diciembre de 2020, como así también una breve reconstrucción histórica de los lugares catalogados.

\section{1.- Cárcel de Carabanchel}

La cárcel de Carabanchel, cuyo nombre oficial fuera el de Prisión Provincial de Madrid, fue edificada con la mano de obra de presos políticos sometidos a trabajos forzados por el régimen franquista para cubrir las necesidades penitenciarias de la ciudad en el año 1940. Funcionó como centro penitenciario hasta el año 1998 en el que cerró sus puertas y finalmente, fue demolida en 2008 con el proyecto de urbanizar el solar que ocupara conforme las demandas de la comunidad, lo que aún no se ha concretado. El Comisionado propuso la colocación de algún elemento suficientemente visible que permita dar a conocer la existencia en aquel lugar del centro penitenciario, su historia, algunos testimonios de los que allí sufrieron condena y movimientos populares surgidos en torno al penal, esto último tampoco se ha llevado a cabo, encontrándose el predio completamente desmantelado y en estado de abandono.

55 Jordi Borja, Revolución urbana y derechos ciudadanos (Editorial Café de las Ciudades 2014) 174. 
Figuras 1 y 2: Predio donde se ubicó la cárcel de Carabanchel

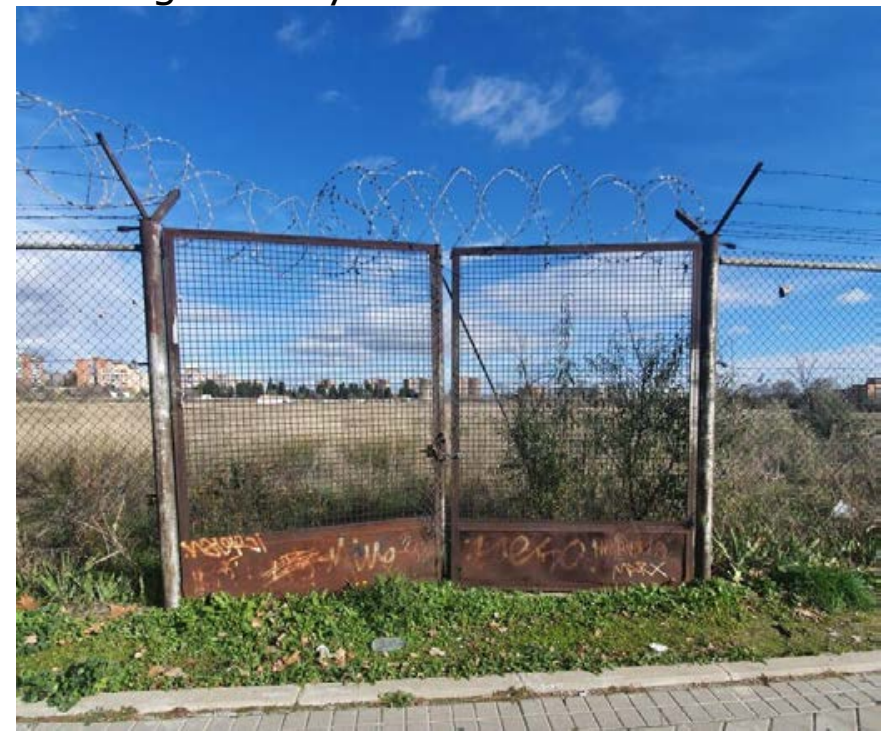

Fuente: archivo personal

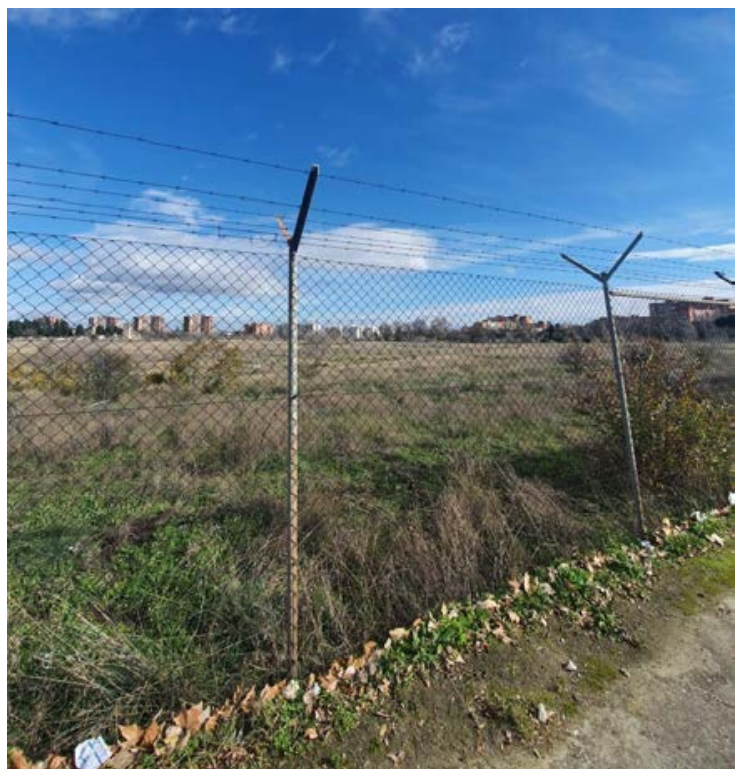

\section{2.- Cárcel de Ventas}

La antigua cárcel de Ventas fue concebida durante la Segunda República como Prisión Modelo de mujeres y se emplazó en la calle Marqués de Mondéjar, muy cerca de la Plaza de toros de la ciudad. Durante los primeros meses de la guerra civil, el centro fue destinado a hombres exclusivamente y desde allí un grupo de doscientos presos fueron conducidos a Paracuellos del Jarama, donde fueron asesinados. Luego, durante el régimen franquista volvió a convertirse exclusivamente en sitio de reclusión de mujeres -la mayoría de ellas detenidas por cuestiones políticas, acusadas de colaborar con la República- y niños, quienes por la sobrepoblación la llegaron a habitar en condiciones muy precarias de vida. En este caso, el Comisionado propuso colocar algún signo visible del lugar donde estuvo la cárcel que se encuentra ocupado hoy por viviendas y un parque público, apoyando el proyecto existente de intervención memorialística promovido por distintas asociaciones del barrio y que cuenta con el apoyo de la Junta de Distrito de Salamanca, sugiriendo también la remisión al período de la Guerra Civil en el que esa cárcel sirvió de prisión a un gran número de personas, algunas de las cuales fueron sacadas de ella para ser fusiladas.

Habiendo recorrido la calle Marqués de Modéjar no se localiza ninguna placa ni conjunto escultórico que conmemore los hechos ocurridos. Ahora bien, existe un sitio de internet del Ayuntamiento de Madrid-Distrito Salamanca del año 2017 (carceldeventas.madrid.es ${ }^{56}$ ) dedicado a las presas políticas que se organizaron dentro de la cárcel en la búsqueda por reconstruir su historia con la ayuda de sus

${ }^{56}$ Fecha de consulta 20/01/21. 
recuerdos, por lo que se recogen diferentes testimonios y el listado de presas ejecutadas.

Figura 3: Calle Marqués de Modéjar donde estaba ubicada la antigua cárcel de Ventas

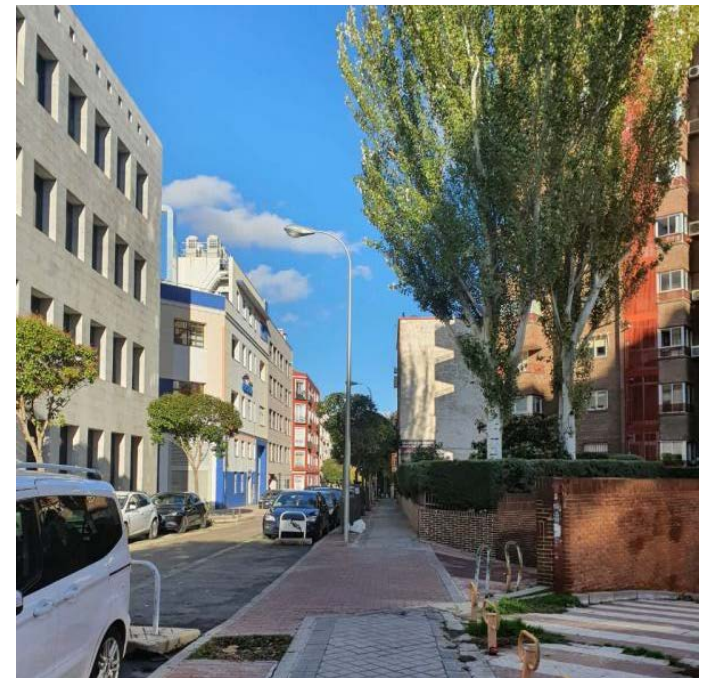

Fuente: archivo personal

\section{3.- Cárcel de Torrijos}

La Cárcel de Torrijos o Prisión Provincial de Torrijos fue una cárcel para hombres y si bien el edificio se planteó inicialmente para que fuese una residencia de ancianas regentada por la congregación de las Hijas de la Caridad -actualmente el asilo de la Fundación Elorz-entre 1939 y 1940 funcionó como la prisión provincial de hombres donde fueron recluidos diversos personajes importantes, entre ellos Miguel Hernández. El escritor tiene dedicada una placa en su memoria y rememoración a su obra, sin embargo no se hace mención a las condiciones de su detención. Al tratarse de un edificio privado, urbano y céntrico, la propuesta que de momento no se ha cumplido consistía en que se coloque una placa explicativa del significado del lugar.

Figura 4: Placa en conmemoración a Miguel Hernández

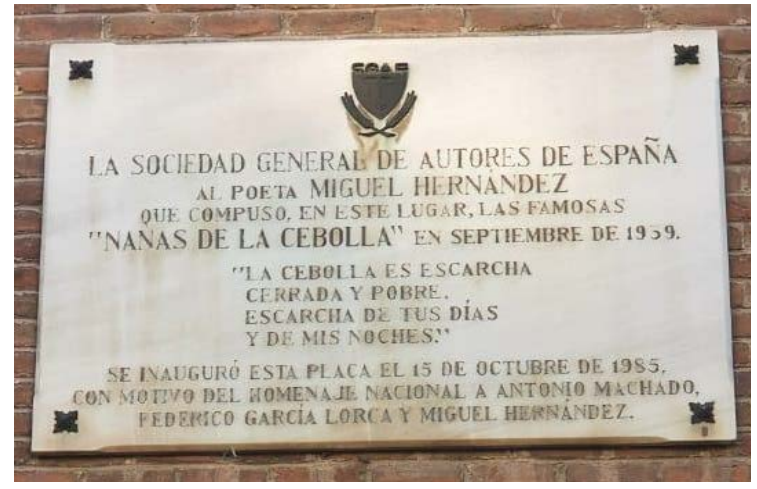

Fuente: archivo personal 
Figura 5: Antigua cárcel de Torrijos, hoy asilo de la Fundación Elorz

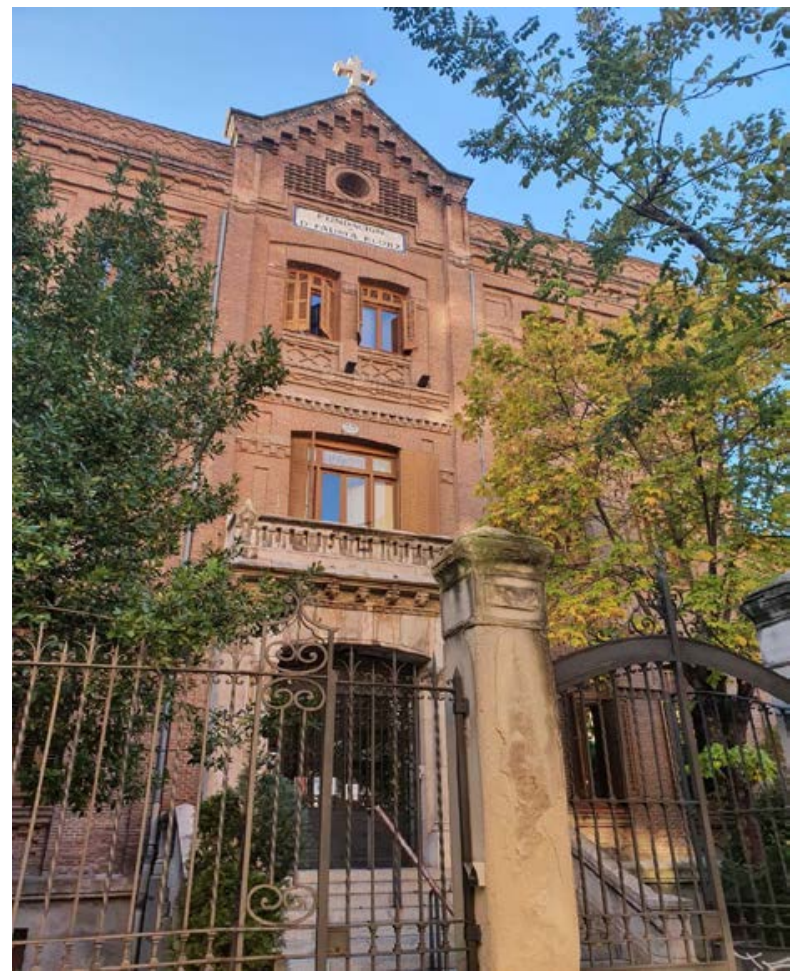

Fuente: archivo personal

\section{4.- Cárcel de Porlier}

La Prisión Provincial de Hombres número 1 o más conocida como cárcel de Porlier funcionó como lugar de detención durante la guerra civil y el comienzo de la posguerra, ocupando las instalaciones del colegio Calasancio. Desde esta cárcel salieron, durante noviembre y diciembre de 1936, presos que luego fueron asesinados en Paracuellos del Jarama. Entre 1939 y hasta 1944, el edificio albergó presos afines a la República, para luego ser devuelto a sus fines educativos los que prevalecen en la actualidad. En virtud de ello, se propuso únicamente la colocación de una placa explicativa del significado del lugar sin haberse efectivizado. 
Figura 6: Antigua cárcel de Porlier

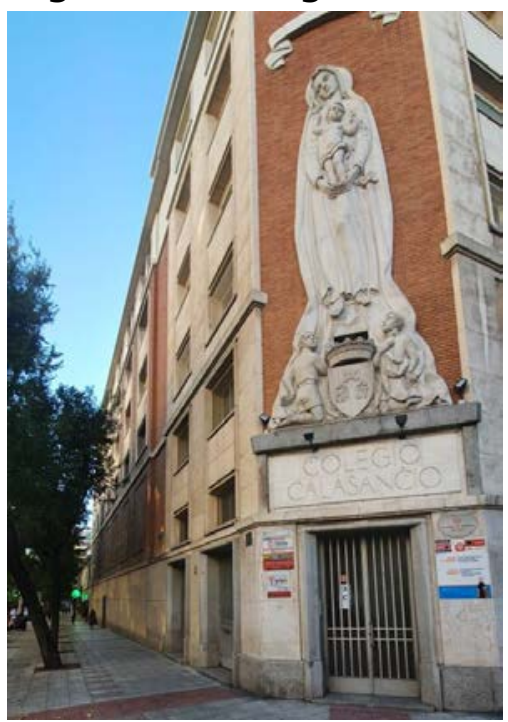

Fuente: archivo personal

\section{5.- Cárcel Modelo}

La cárcel Modelo o cárcel celular fue construida durante el último cuarto del siglo XIX y estuvo operativa hasta su demolición en 1939 tras recibir importantes daños durante la Guerra Civil. Actualmente en su lugar se erige el Cuartel general del Ejército del Aire. Por sus 1.200 celdas pasaron antes de la guerra civil conocidos falangistas como José Antonio Primo de Rivera o Rafael Sánchez Mazas, luego del incendio del 22 de agosto de 1936 fue ocupada por milicianos que asesinaron a diversos políticos y militares miembros del Comité Revolucionario Republicano, poco antes de la proclamación de la Segunda República. Se propuso la colocación de una placa explicativa en el edificio que ocupa actualmente el espacio donde estuvo la cárcel, no observándose señalización alguna en su relevamiento.

Figura 7: Predio donde estaba ubicada la antigua Cárcel Modelo

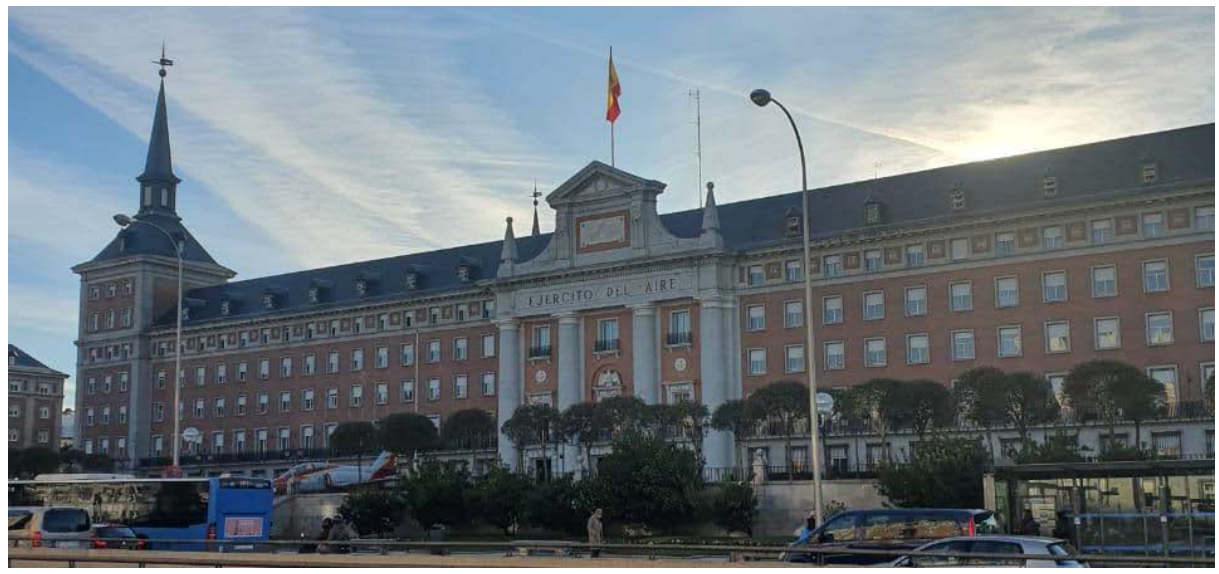

Fuente: archivo personal 


\section{6.- Cárcel de Yeserías}

En un primer momento, la construcción realizada del edificio por el Ayuntamiento de Madrid tenía como fin ser asilo para mendigos o indigentes. Luego de finalizada la Guerra Civil se convirtió en un establecimiento carcelario masculino destinado a alojar presos políticos. En 1943 pasó a ser Hospital Penitenciario Eduardo Aunós y posteriormente, con el cierre y demolición de la cárcel de Ventas, se convierte en cárcel de mujeres. Desde la última década del siglo pasado funciona como Centro de Inserción Social Victoria Kent, por lo que la propuesta consiste en colocar una placa explicativa del significado del lugar no constando referencia alguna en el ingreso al edifico.

Figuras 7 y 8: Fachada de ingreso al Centro de Inserción Social Victoria Kent
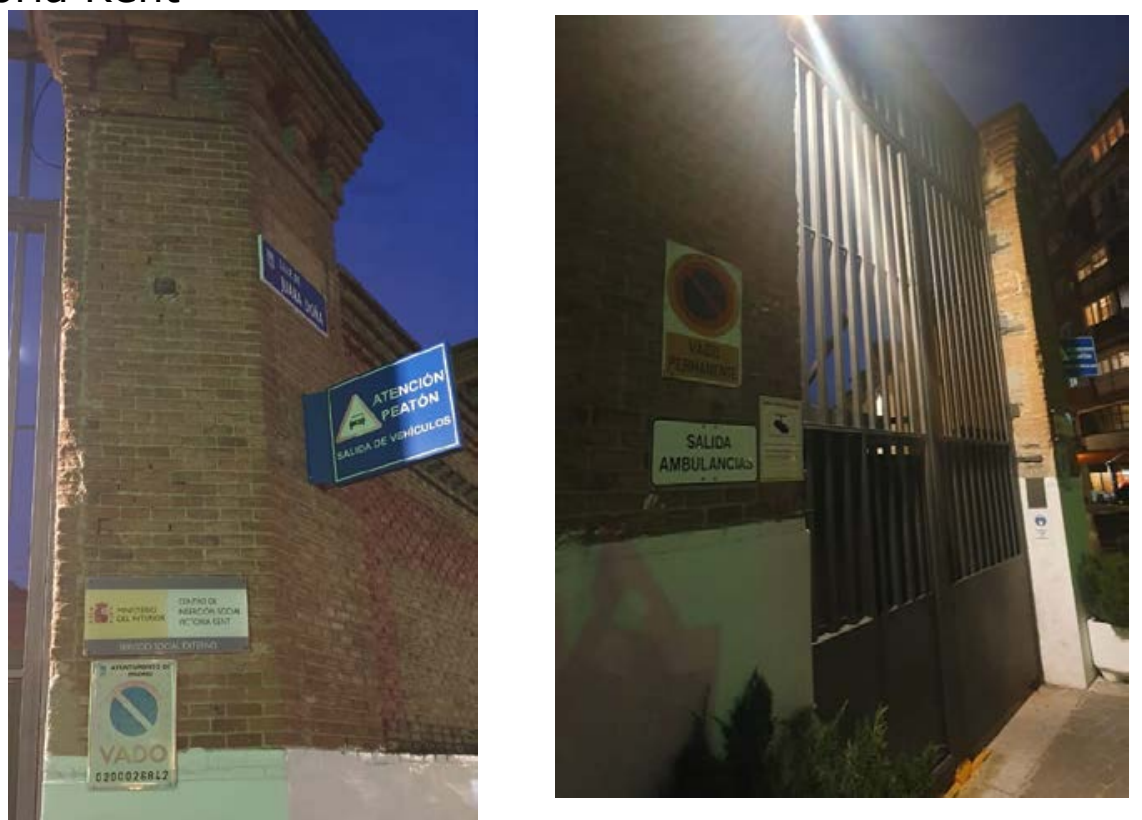

Fuente: archivo personal

\section{7.- Checa Bellas Artes - Fomento}

En 1936 se creó el Comité Provincial de Investigación Pública que funcionó en lo que actualmente es el edificio del Círculo de Bellas Artes, en la calle Alcalá, 42. Poco tiempo después se trasladó a un edificio sito en el no 9 de la calle Fomento, que funcionó como una checa exclusivamente de detenciones de personas sospechosas de simpatizar con los sublevados o de perfil conservador. En la actualidad funciona en el lugar el I.E.S. Santa Teresa de Jesús, proponiéndose la colocación de una placa explicativa en el edificio donde se ubicó esta checa. El Presidente del Círculo de Bellas Artes-Fomento se opuso a la colocación de la placa sugerida, el Comisionado mantuvo su postura 
expresamente aunque no hay señalización alguna que rememore lo allí ocurrido.

Figura 9: I.E.S. Santa Teresa de Jesús

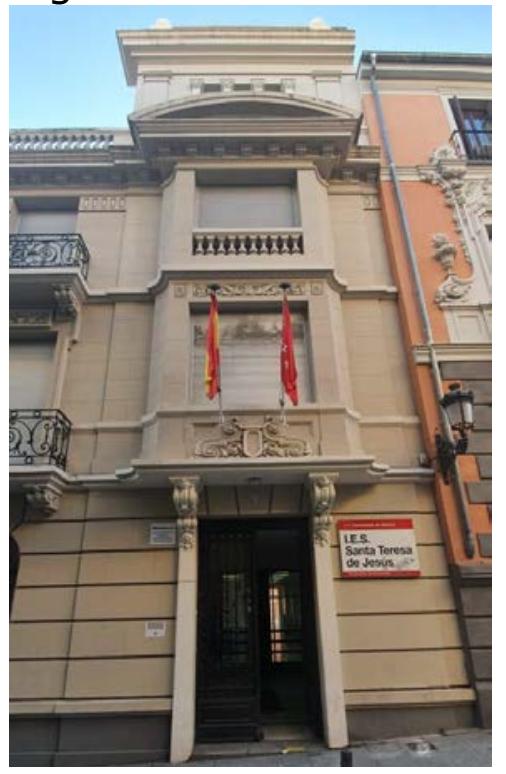

Fuente: Archivo personal

\section{8.- Cementerio de Fuencarral}

En el cementerio de Fuencarral fueron enterrados muchos combatientes republicanos y brigadistas internacionales. Finalizada la guerra civil sus cuerpos fueron exhumados y abandonados o arrojados a una fosa común. En recuerdo a estos hechos es que restablecida la democracia las embajadas internacionales instalaron varios memoriales en conmemoración a los brigadistas y también un monumento memorial a los combatientes españoles contra el nazismo en la Segunda Guerra Mundial.

El Comisionado propone colocar en el cementerio el símbolo externo que identifique los lugares de memoria de Madrid y la posibilidad de habilitar espacio en el muro donde se hallan colocadas las placas por parte de las distintas embajadas. Sin perjuicio de ello, no se observan cambios en las fotos insertas en el informe del Comisionado respecto de la situación actual que presenta el lugar, ni tampoco la placa que lo identifique como lugar de memoria de Madrid en el ingreso. 
Figuras 14 y 15: Memorial en conmemoración a los brigadistas internacionales
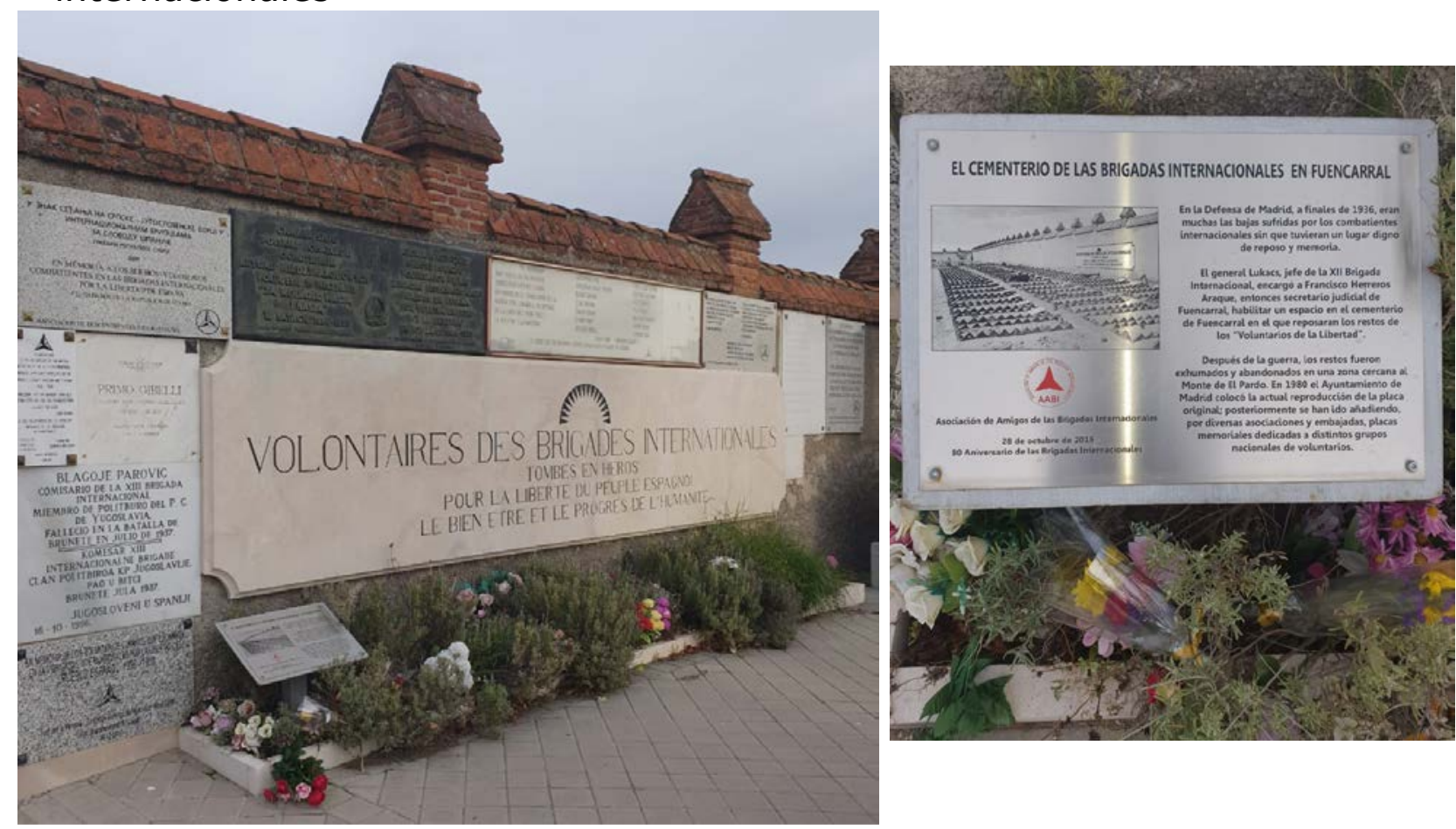

Fuente: archivo personal

\section{9.- Arco de la Victoria}

El Comisionado propuso que se proceda a la resignificación del monumento mediante su cambio de nombre por 'Arco de la Memoria'; un estudio y modificación o explicación de la leyenda y de los signos externos, una intervención en el área externa al monumento que permita el acceso peatonal y su inserción en la estructura urbana y, por último el uso del espacio interior para ubicar en su parte disponible una exposición permanente relacionada con el objeto por el que fue erigido el Arco. Sin perjuicio de lo antes declarado, lo cierto es que no se renombró, señalizó ni tampoco se hicieron las intervenciones sugeridas en el lugar, resultando de muy difícil acceso para los peatones al estar rodeado de grandes avenidas y carecer de las respetivas sendas. 
Figura 16: Arco de la Victoria

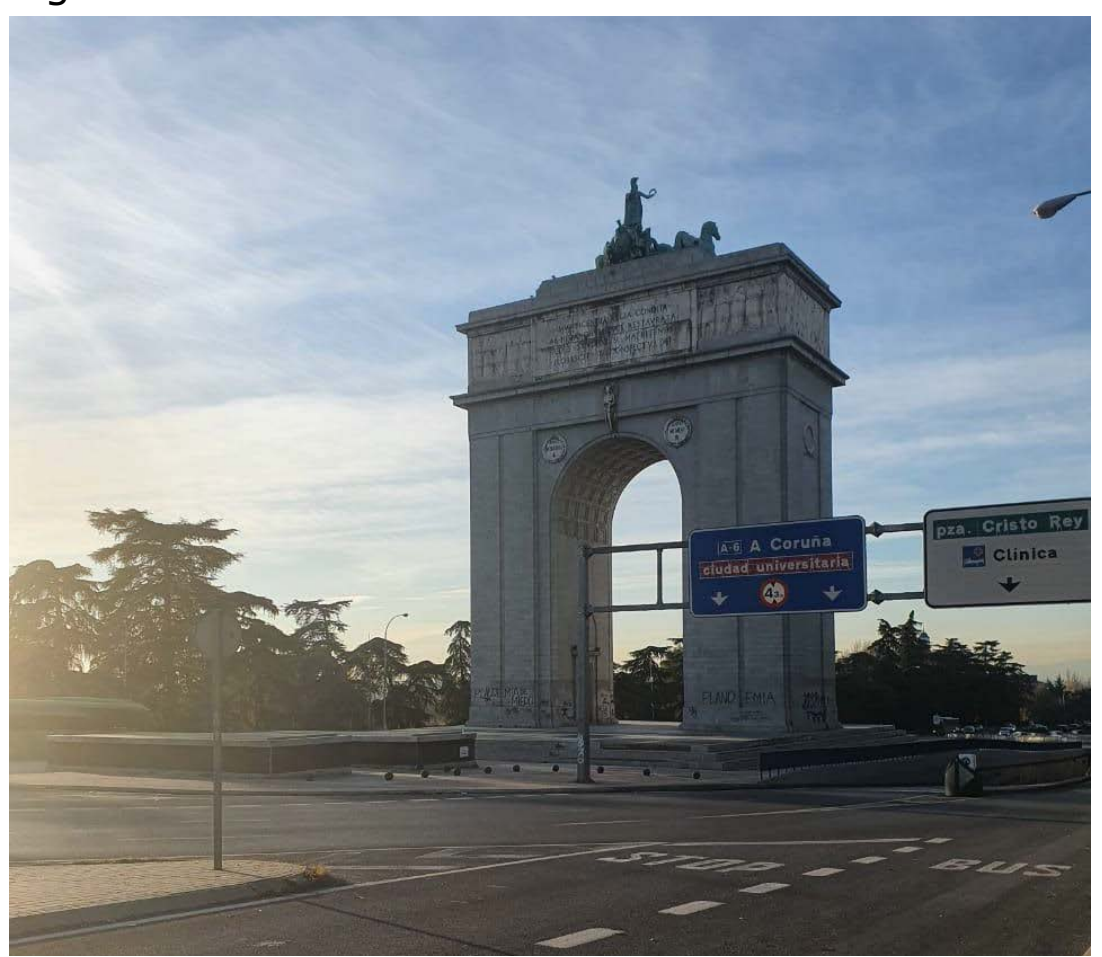

Fuente: archivo personal

\subsection{0.- Edificio sede de la Presidencia de la Comunidad de Madrid, en la Puerta del Sol}

En el edificio emblemático ubicado en Puerta del Sol, sede de la Presidencia de la Comunidad de Madrid, funcionó luego de la Guerra Civil la Dirección General de Seguridad, ubicando en sus sótanos calabozos en los que se alojaba y frecuentemente se torturaba detenidos miembros de la oposición al régimen. El Comisionado propuso que con acuerdo de la Presidencia de la Comunidad de Madrid, se coloque una placa distintiva explicativa y se habilite los calabozos existentes para que puedan ser visitados con propósito pedagógico. Nada de ello ha ocurrido, en su exterior se visibilizan tres placas en conmemoración a los héroes que combatieron el 02 de mayo de 1808 contra las tropas de Napoleón, en recuerdo de las víctimas de los atentados del 11 de marzo de 2004 y agradecimiento a todos aquellos que prestaron ayuda y, por último, en recuerdo a las víctimas de la reciente pandemia por COVID-19, pero no se hace referencia alguna a su calidad de lugar de memoria. 
Figura 17: Edificio sede de la Presidencia de la Comunidad de Madrid

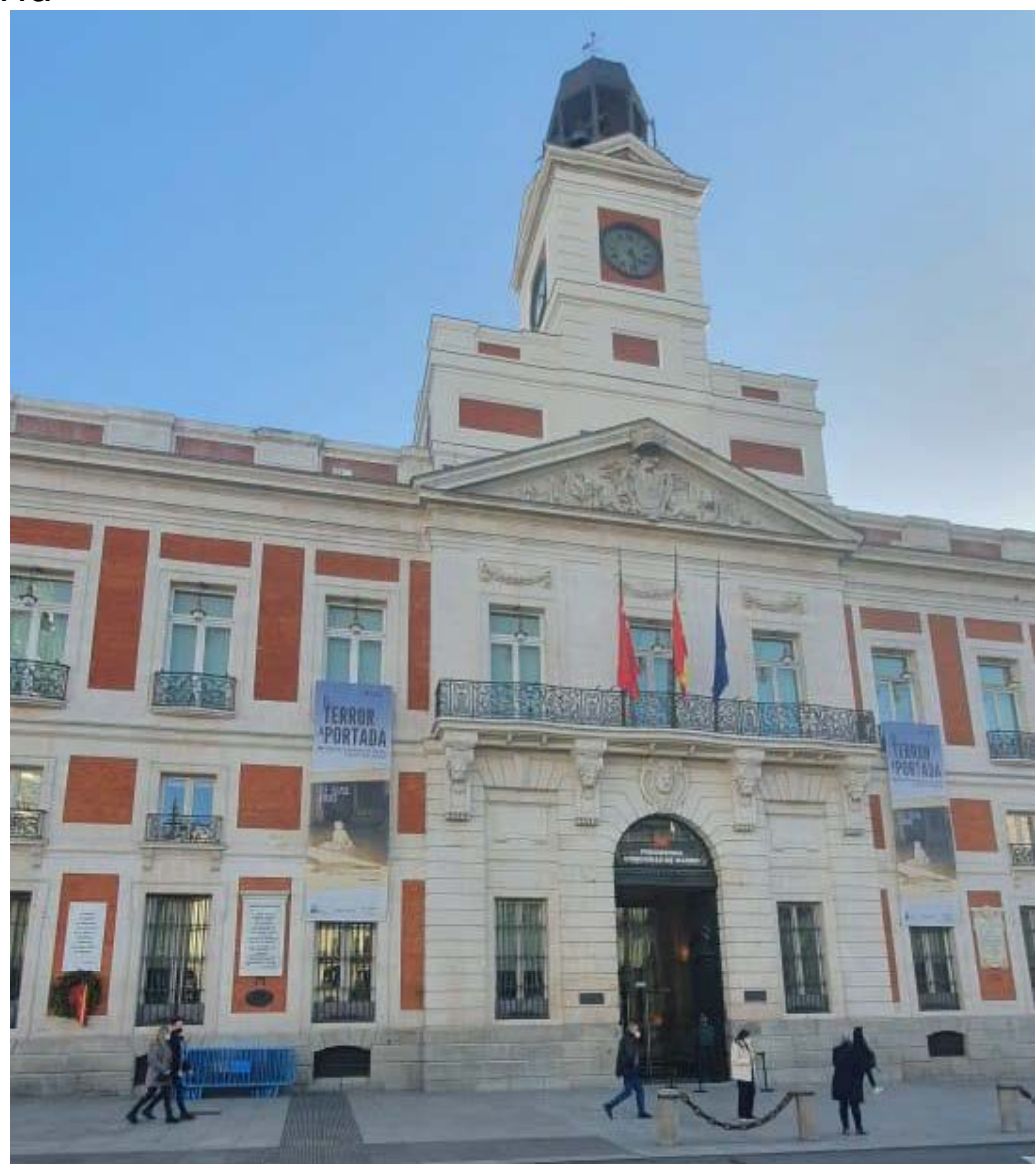

Fuente: archivo personal

\subsection{1.- Colina de los Chopos}

Se denominó Colina de los Chopos al conjunto de edificios ubicados en los altos del Hipódromo, al final del paseo de la Castellana. El complejo estaba formado por la Junta para Ampliación de Estudios, el Instituto Escuela y la Residencia de Estudiantes, entre otros, pero al finalizar la guerra civil se decidió desmantelarlo y se cambió su finalidad. De este modo, se ubicaron en su lugar el Consejo Superior de Investigaciones Científicas (CSIC) y el Instituto Ramiro de Maeztu. El Comisionado, tuvo en cuenta las iniciativas de memoria ya existentes en distintos edificios del lugar y propuso la colocación de una placa en el Instituto Ramiro de Maeztu lo que no se concretó. 
Fiigura 18: Instituto Ramiro de Maeztu

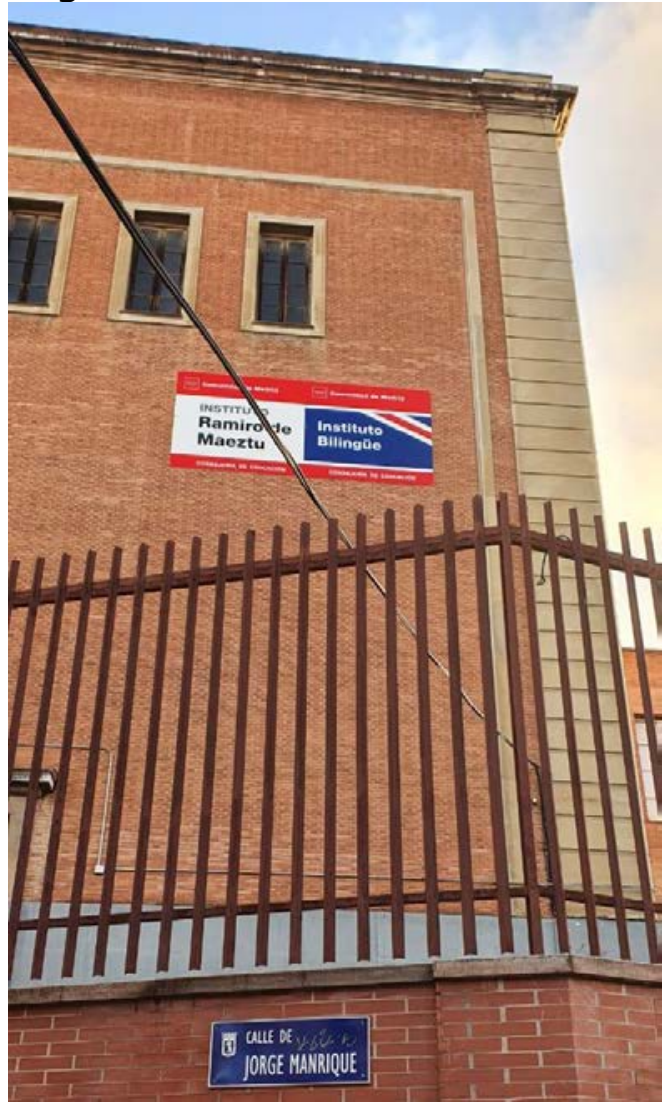

Fuente: archivo personal

\subsection{2.- Colegiata de San Isidro}

Es un templo católico construido por la Compañía de Jesús en el siglo XVII y antigua catedral de Madrid hasta 1992, ubicado en el barrio de La Latina. El 19 de julio de 1936, días después de la sublevación militar, la colegiata sufrió un incendio intencionado, destruyéndose en él numerosas obras de arte, suponiendo la pérdida irreparable de patrimonio artístico y quedando dañada la estructura del edificio. El Comisionado propuso la colocación de una placa, pero en este lugar tampoco hay referencia alguna a lo acontecido. 
Figura 19: Ingreso a la Colegiata de San Isidro

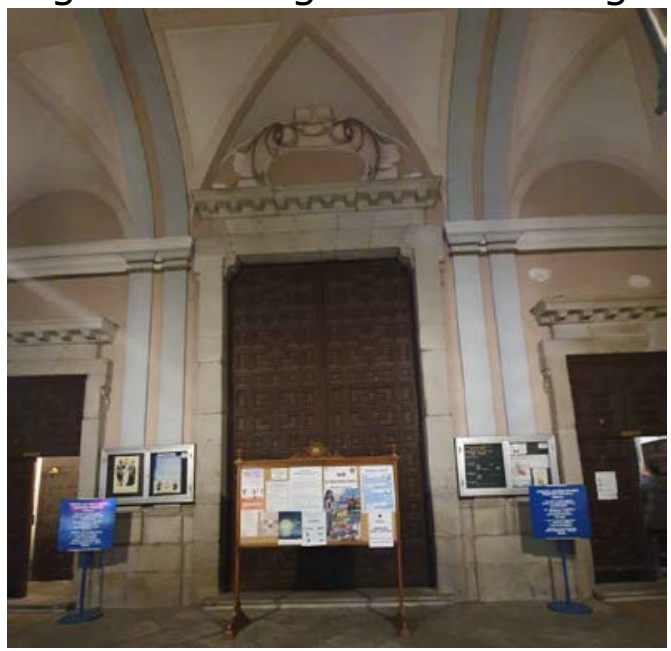

Fuente: archivo personal

\subsection{3.- Bunker del Capricho}

En el parque de El Capricho, justo al lado del palacio de la duquesa de Osuna, que fuera construido en el siglo XVIII, se conservó en muy buen estado un bunker utilizado durante la Guerra Civil por el Cuartel General del Ejército del Centro. El Comisionado sugirió en su propuesta poner una placa o bien incorporar el logo que identifique los lugares de memoria de Madrid. En la observación realizada, se visualizan dos entradas cerradas con placas que lo identifican como "BUNKER", pero no así explicación alguna de su origen ni tampoco su identificación como lugar de memoria de la ciudad. Sin perjuicio de ello, la Dirección General de Patrimonio Cultural del Ayuntamiento realiza visitas guiadas que deben ser reservadas con anticipación mediante la web oficial.

Figuras 20 y 21: Entradas al búnker en el Parque El Capricho

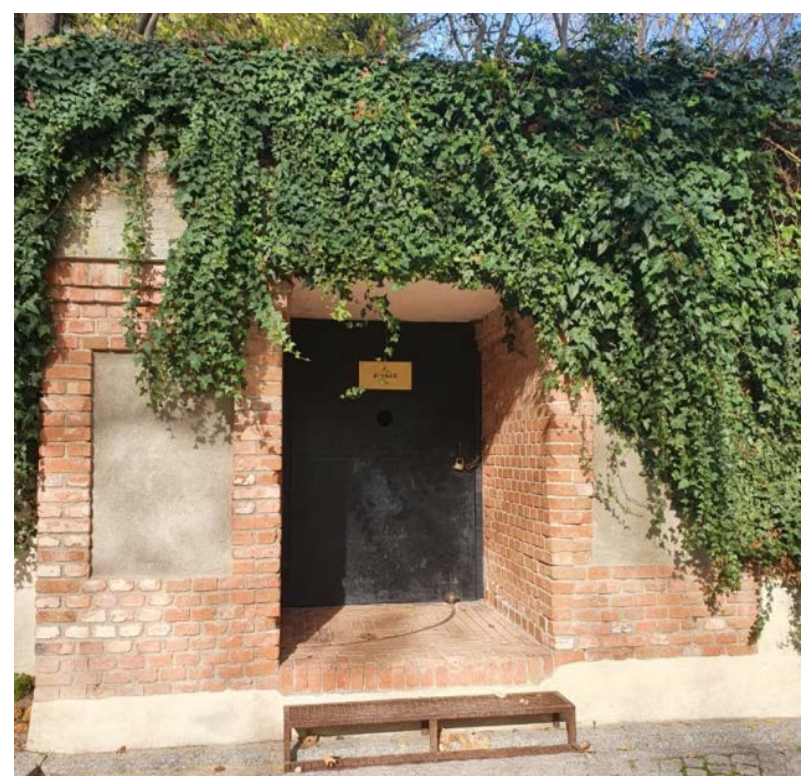

Fuente: archivo personal

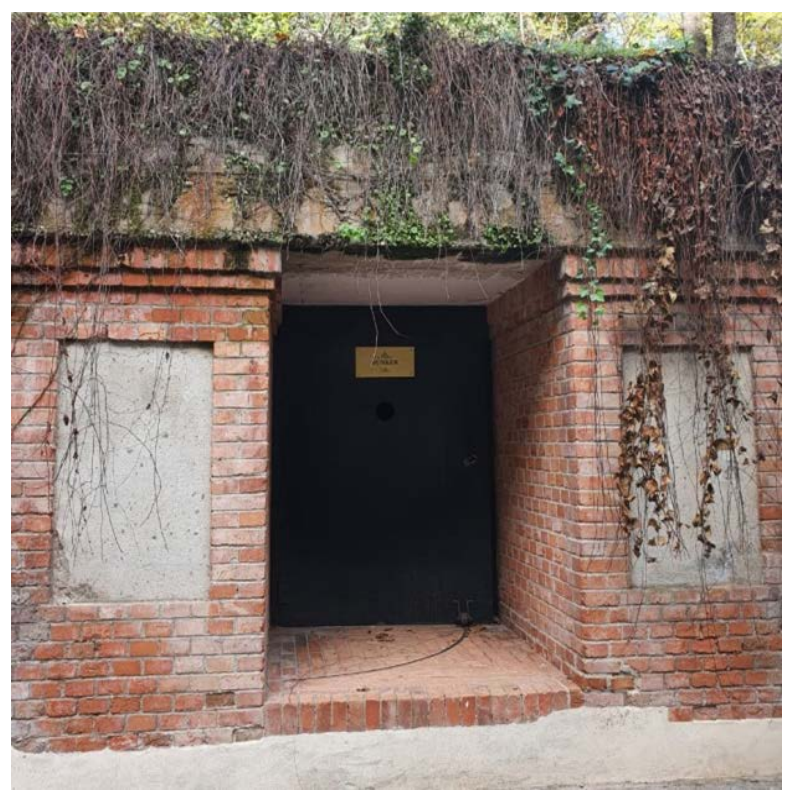




\subsection{4.- Congreso de los Diputados}

Durante la Guerra Civil fueron asesinados 151 diputados (78 del partido republicano y 73 opositores/sublevados) de los poco más de 1.000 que desempeñaron la representación parlamentaria durante las tres legislaturas que se sucedieron durante el periodo republicano. Además, hay que sumar otros 34 casos que se produjeron durante la dictadura luego de finalizada la guerra. El Comisionado solicitó al Ayuntamiento que traslade al Congreso de los Diputados la sugerencia de que, de alguna manera, se deje constancia de ese atentado a la soberanía nacional y a la voluntad de concordia que debe presidir la convivencia. Ahora bien, la observación realizada al lugar muestra las dificultades para el acercamiento que presenta a la comunidad, su entrada principal ubicada en Plaza de las Cortes tiene vallas que impiden aproximarse y el acceso de Calle de Zorrilla en días laborales presenta una gran vigilancia de fuerza policial. En estas circunstancias, no se visibiliza ninguna marca que lo identifique como lugar de memoria.

Figuras 22 y 23: Ingresos al Congreso de los Diputados por Plaza de las Cortes (izquierda) y por Calle de Zorrilla (derecha)
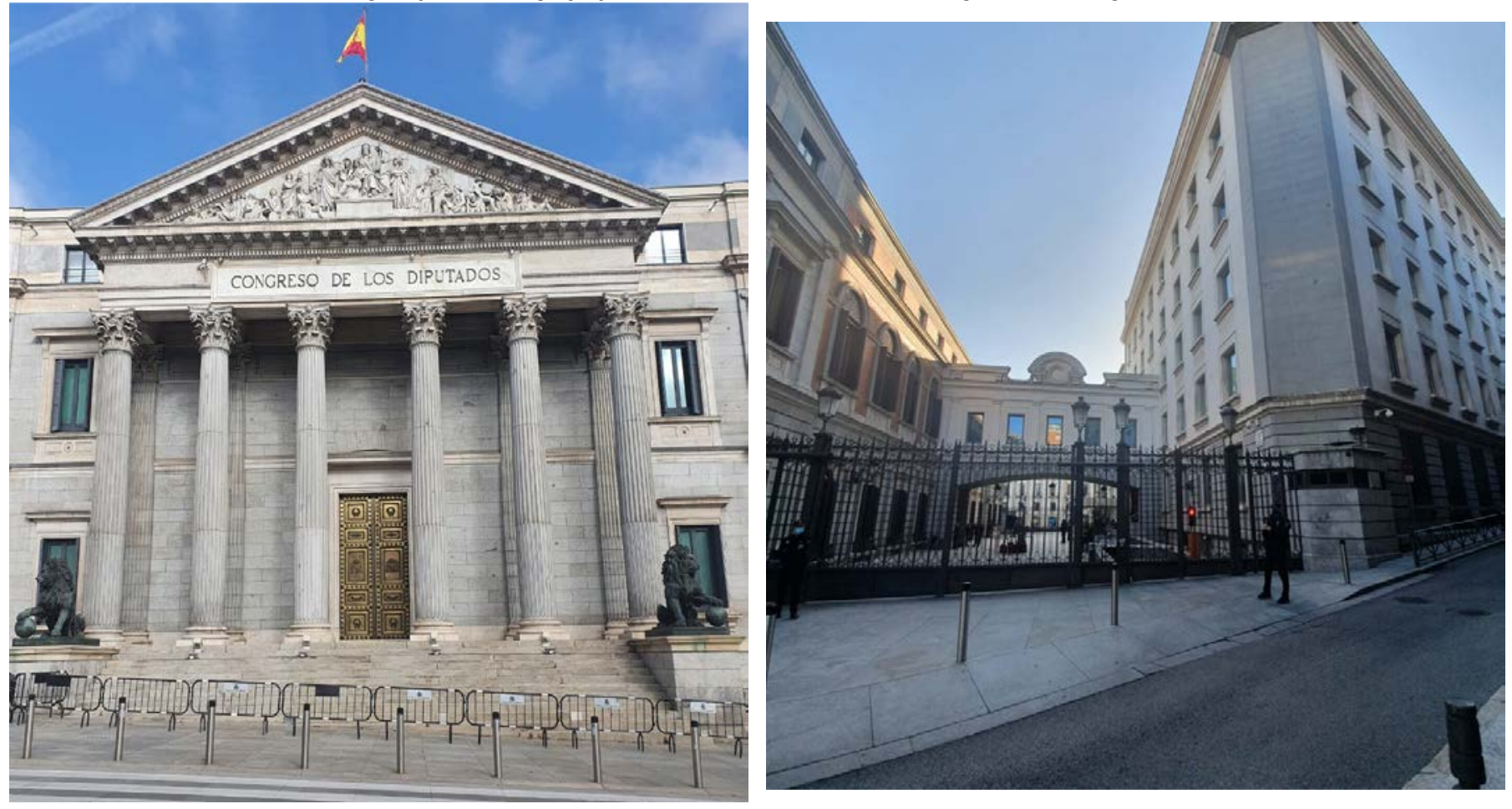

Fuente: archivo personal

\subsection{5.- Cementerio del Este}

El actual cementerio de La Almudena fue escenario de la durísima represión de la posguerra. Se calcula que, entre los años 1939 y 1945, más de 2.600 personas fueron fusiladas en sus tapias y otros tantos enterrados, surgiendo un total aproximado de 3.000 personas del 
registro de enterramientos del cementerio. Actualmente se conserva un trozo de una de las tapias originales del recinto, que permite ubicar el lugar de las ejecuciones. El Comisionado toma la idea de intervención escultórica en la parte izquierda de la entrada principal del cementerio, próximo a los restos de la tapia como así también la creación de un centro documental en el lugar.

Al ingresar por la puerta de calle O'Donell a pocos pasos hacia la izquierda se observa el memorial donde fueran colocadas las placas por el Ayuntamiento bajo el gobierno de Carmena con los nombres de los republicanos fusilados y que luego fueran retiradas con el cambio de dirección política a manos del Partido Popular y Ciudadanos. En virtud de lo recomendado oportunamente por el Comisionado se fundamentó que el memorial no cumplía con el fin de honrar a todas las víctimas del periodo bélico. Actualmente, se lee una frase en el centro del memorial que reza: "El pueblo de Madrid a todos los madrileños que entre 1936 y 1944, sufrieron violencia por razones políticas, ideológicas o por sus creencias religiosas. Paz, piedad y perdón". Las disputas Ilevaron a que la Asociación Memorialista Ranz Orosas denunciara ante la justicia el retiro de las placas alegando que el Ayuntamiento incurrió en el delito de prevaricación.

Figuras 10 y 11: Memorial en el ingreso al cementerio (izquierda) y antigua tapia con placa conmemorativa

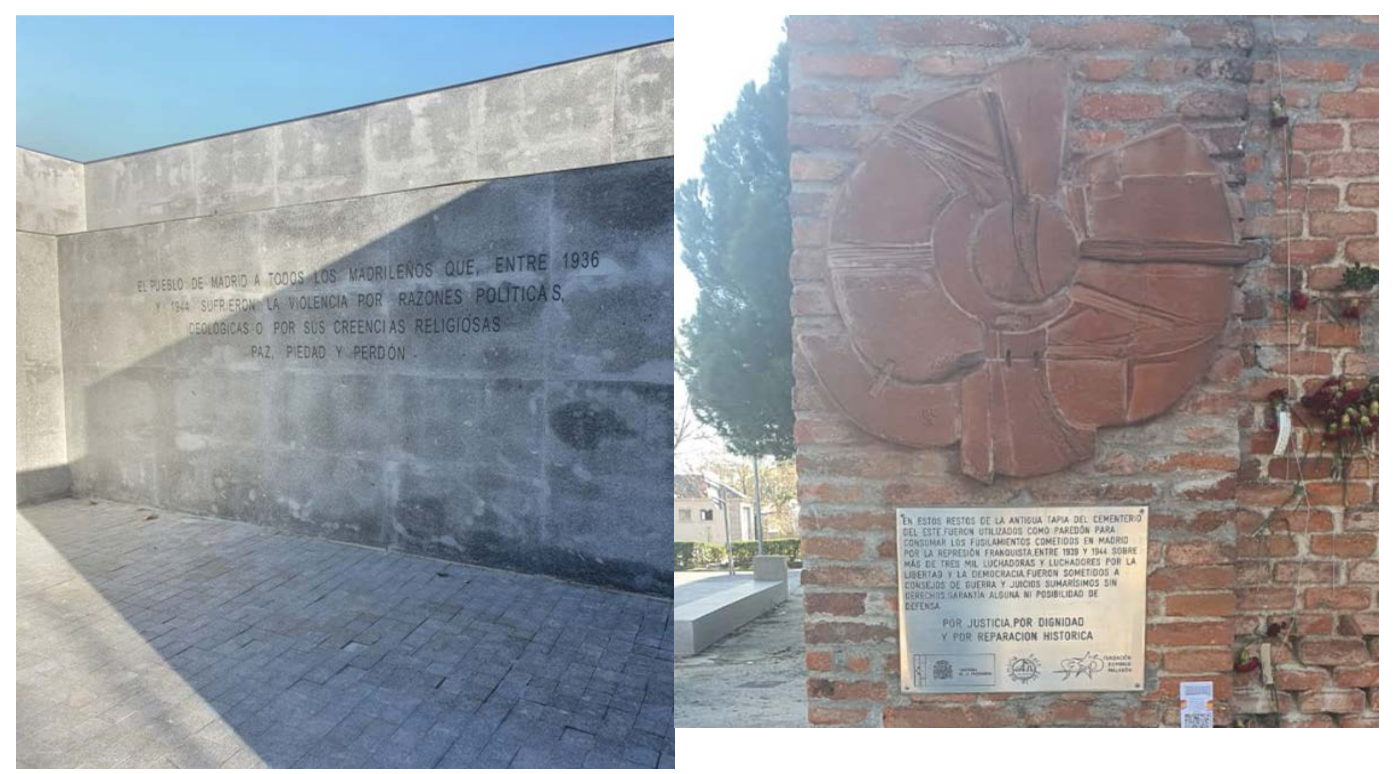

Fuente: archivo personal

En frente, se observa el resto de tapia original, con una placa que hace alusión a los fusilamientos allí ocurridos colocada por Ministerio de la Presidencia, Foro por la memoria y Fundación Domingo Malagón, como así también un código QR para acceder al nombre de las víctimas. Llama la atención un mensaje colocado junto con las flores que manifiesta "Por mucho se esfuercen en haceros invisibles vuestro recuerdo está cada día más presente", es así que pese a no saber el 
origen de dicho mensaje lo cierto es que los espacios físicos donde se llevaron a cabo violaciones a los derechos humanos resultan de vital importancia para el recuerdo de la comunidad y la conmemoración a las víctimas, son ámbitos propicios donde inscribir la memoria.

Figuras 12 y 13: Imágenes de la antigua tapia
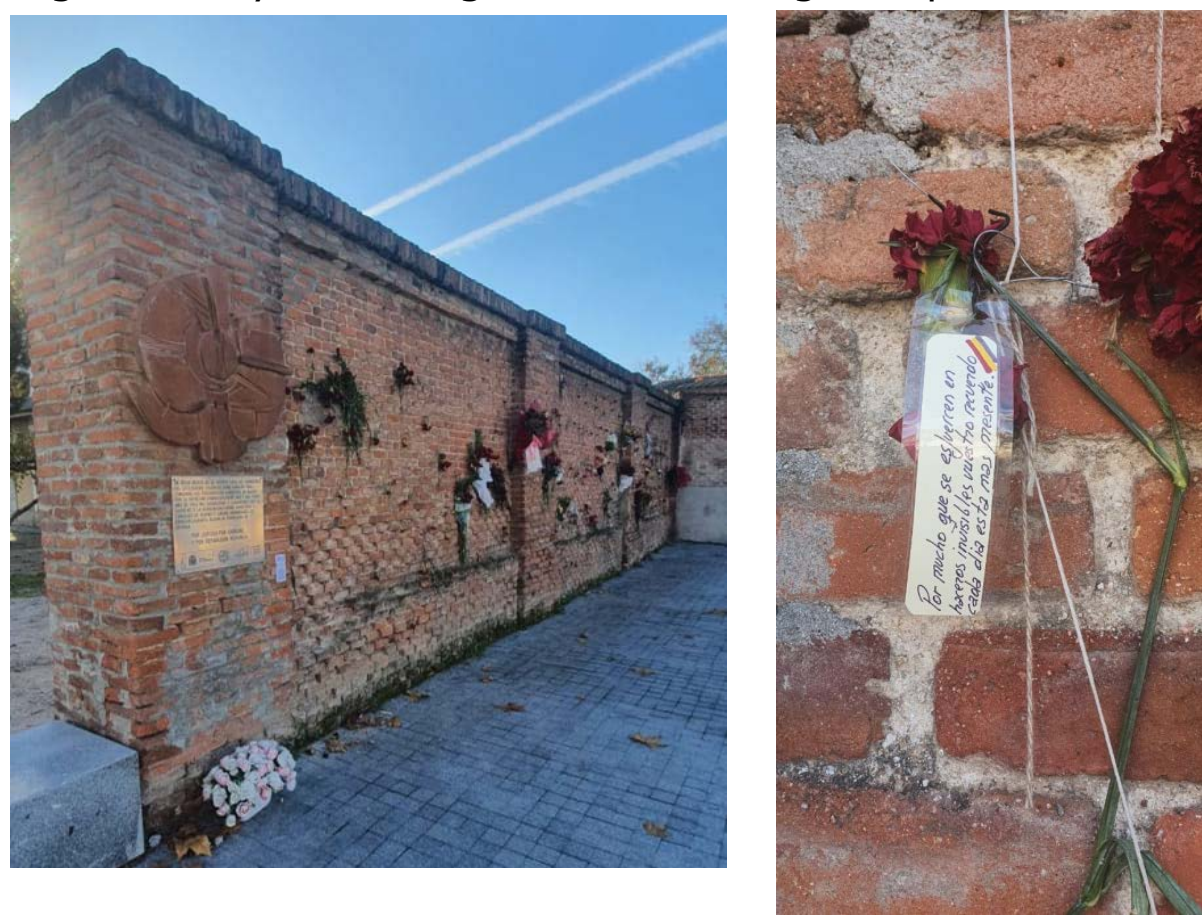

Fuente: archivo personal

Se realizó una entrevista en profundidad semiestructurada, mediante la que se buscó acceder al discurso de una actora social y política que participó en el reclamo judicial presentado por el retiro de las placas en el lugar. Resultando adecuada esta metodología para el caso en tanto las entrevistas en profundidad constituyen un proceso comunicativo por el cual se extrae información contenida en la biografía del entrevistado, relacionada con acontecimientos vividos por él, es decir que ha sido experimentada e interpretada por la persona ${ }^{57}$.

En cuanto a la unidad de análisis, la informante fue seleccionada mediante la técnica de muestra de casos sumamente importantes para el problema analizado ${ }^{58}$, focalizando en su trayectoria tanto relevante como actual en el campo de estudio como así también la accesibilidad y posibilidad de contacto. La informante desarrolla su labor en la temática hace más de siete años tanto en Memoria Histórica del PSOEMadrid como también en la Asociación Memorialista AMRO, manifestó que su implicancia fue en crecimiento "en la consecución de la

\footnotetext{
${ }^{57}$ Alberto Marradi, Nélida Archenti y Juan Ignacio Piovani, Metodología de las ciencias sociales (Emecé Editores 2007).

58 Roberto Hernández Sampieri, Carlos Fernández Collao y Pilar Baptista Lucio, Metodología de la investigación (McGraw-Hill Interamericana 2006).
} 
reparación de los miles de casos que aún tenemos pendientes en España".

En relación a sus percepciones respecto del estado del debate sobre los lugares de memoria en Madrid y su reconocimiento en el espacio público, destaca que:

\begin{abstract}
"en la actualidad en Madrid hay dos debates abiertos. Uno político, y absolutamente partidista, donde por parte del partido del gobierno regional y local, pretenden eliminar todo tipo de simbología relacionada con la memoria democrática, y lo que es más importante el incumplimiento de la propia ley de Memoria Histórica de manera sistemática y premeditada, menospreciando a los miles de madrileños y madrileñas que aún se encuentran desaparecidos o sin un reconocimiento expreso (....) Lamentablemente en Madrid el reconocimiento a la memoria democrática y a los lugares de memoria, brilla por su ausencia. Por otro lado se encuentra el debate dentro del ámbito asociativo. En este punto las asociaciones cuentan con el apoyo de partidos de izquierdas como el PSOE, para no dejar que la derecha acabe con el recuerdo de una dictadura que tanto daño hizo en Madrid. La elaboración de un catálogo de vestigios por parte del Ayuntamiento de Madrid, en el mandato pasado, nos dejó una base de debate y discusión acerca de los lugares de memoria y su posible resignificación".
\end{abstract}

Respecto de la importancia de las inscripciones espaciales de la memoria para la comunidad local en términos de derechos, la entrevistada refirió que los espacios "tendrán un valor más moral y de reparación que legal, ya que son lugares de reconocimiento y recuerdo de aquellos que sufrieron persecución, violencia, vejación, o privación de libertad por defender las libertades y la democracia".

Finalmente, en virtud de la presentación de la denuncia realizada por la AMRO por el retiro de las placas del cementerio de La Almudena, se le consultó sobre las repercusiones del incidente dada su participación:

\begin{abstract}
"Desde AMRO presentamos el caso a la fiscalía y al Tribunal de Cuentas, porque entendíamos que el procedimiento podría incurrir en presuntos casos de malversación de caudales públicos, ya que dicho memorial, había costado a las arcas madrileñas cerca de $300.000 €$. El memoria, ya estaba construido y la alternativa del gobierno municipal de Almeida fue su destrucción. El procedimiento fue archivado 1 años después, aproximadamente.

Desde entonces, diferentes asociaciones memorialistas, organizan actos de recuerdo y reconocimientos, donde hoy están los escombros de lo que queda del memorial. Ellas mismas presentaron diferentes escritos de rechazo a su destrucción y no pierden la esperanza de que se vuelvan a poner los nombres de las víctimas, borradas por segunda vez de nuestra historia".
\end{abstract}

\title{
5.- CONCLUSIONES
}

La teoría crítica de los derechos humanos asumida en la investigación apoyó el análisis del derecho a la memoria y el derecho a la ciudad como producto de las luchas sociales en busca de la dignidad humana, la emancipación y con una perspectiva adoptada desde las víctimas de las graves violaciones a los derechos humanos 
que permite su visibilización, por lo que actúa como reparación pero también contribuye en la promoción de los derechos humanos en la actualidad bajo la premisa de 'no repetición'.

Desde una dimensión jurídica basada en un enfoque de derechos y con perspectiva espacial se concluyó que ambos derechos humanos se encuentran interrelacionados y son interdependientes. El derecho a representar el pasado en el espacio público que tiene la ciudadanía puede considerarse como parte del derecho a la ciudad, en tanto las ciudades tienen 'heridas' provocadas por los pasados dictatoriales que hacen necesaria la recuperación y construcción de la memoria colectiva de lo ocurrido para afianzar la democracia en los procesos de justicia transicional.

Específicamente se tomaron las inscripciones espaciales de la memoria en la ciudad como punto de contacto entre el derecho a la memoria y el derecho a la ciudad para el análisis, en tanto ellas no sólo actúan como soporte de la memoria colectiva en las ciudades sino que también resultan ser espacios favorables donde pueden concebirse alternativas de una sociedad más justa y equitativa en términos de Derechos Humanos, colaborando en los procesos de democratización de la ciudad.

La apropiación y resignificación de espacios y lugares permiten articular políticas públicas de memoria que no están exentas del debate, pero que permiten la reflexión, la construcción de una ciudadanía respetuosa de los derechos humanos y el fortalecimiento de los pilares democráticos. Rescatar lo ocurrido en sitios específicos de la ciudad mediante su señalización o incluso refuncionalización, son políticas que contribuyen a reparar simbólicamente a las víctimas y a la sociedad en su conjunto.

El derecho a la ciudad incluye no sólo derechos sociales y la redistribución de bienes y servicios públicos, sino que también implica reconocer la participación en la producción del espacio público de la ciudad. De esta manera, el espacio público puede ser apropiado por los sujetos para inscribir la memoria social. Ésta memoria es parte constitutiva de la identidad del grupo, construye un sentido de comunidad, lazos compartidos y permite establecer un sentimiento de pertenencia en relación al especio en el que se inscribe.

En relación al caso de estudio seleccionado, lo cierto es que en la ciudad de Madrid no se han recuperado sus lugares de memoria y menos aún se ha logrado inscribir la memoria democrática en el espacio público. Es así que no se cumple con los estándares internacionales ni regionales de derechos humanos en la materia como tampoco con lo que dispuso -aunque con limitaciones- la Ley de Memoria Histórica $n^{\circ}$ 52/2007.

Si bien la ley hace referencia a la supresión de determinados símbolos y monumentos del espacio público en su artículo 15 , no se ha concretado la modificación del callejero en la ciudad ante las diferentes dilaciones y oposiciones a lo sugerido por el Comisionado de la Memoria Histórica del Ayuntamiento de Madrid. 
Similar suerte corrió la propuesta de lugares de memoria también elaborada por el Comisionado que durante todo el año que cumplió funciones relevó y estableció como se debía inscribir la memoria en quince lugares representativos para recuperar la memoria histórica en la ciudad. Actualmente, los sitios no se encuentran señalizados ni difundidos según el rol que cumplieron en el pasado, sólo se realizan visitas guiadas con cupos limitados a los búnker del Parque El Capricho. Además, se produjo un retroceso en el caso del cementerio del Este al retirar el memorial dedicado a las víctimas sin intentar llegar a un consenso pese a las disidencias que éste acarreaba y propició un reclamo judicial llevado adelante por la Asociación Memorialística AMRO que no prosperó.

Ahora bien, el reciente anteproyecto de Ley de Memoria Democrática significa una oportunidad para saldar estas ausencias de políticas públicas y un notorio avance al ampliar su objeto y finalidad a la promoción de la reparación moral y de la recuperación de la memoria colectiva.

En síntesis, los resultados de esta investigación muestran que pese a que las inscripciones espaciales de la memoria garantizan en los procesos de justicia transicional no sólo el derecho a la memoria sino también el derecho a la ciudad, con acciones que parten desde el pasado pero se orientan al presente y al futuro, en la ciudad de Madrid aquellos sitios que son emblemáticos para representar y entender el pasado dictatorial de España continúan siendo "lugares de olvido" como afirmara Javier Rodrigo ${ }^{59}$. Sin embargo, se advierte como oportunidad para terminar con estas deudas no sólo el anteproyecto de Ley de Memoria Democrática sino también la labor y lucha diaria de los actores sociales que pese a las disputas políticas y partidarias que surgen en torno a la memoria, siguen promoviendo la recuperación de la memoria de las víctimas no sólo como reparación sino como derecho de toda la comunidad.

\section{6.- BIBLIOGRAFÍA}

Adorno T, Epistemología y Ciencias Sociales (Ediciones Cátedra 2001 [1972]).

Arias Marín A, 'Teoría crítica y derechos humanos: hacia un concepto crítico de víctima' [2012] 36 Nómadas. Revista Crítica de Ciencias Jurídicas $y$

Sociales <http: redalyc.org/articulo.oa?id=18126450009> acceso 29 Abril 2021.

Bettanin C, 'Territorio marcado: memorias sobre la dictadura en la ciudad de Avellaneda' [2017] Revista de trabajo social 41.

\footnotetext{
59 Javier Rodrigo, 'Políticas de la memoria, lugares del olvido. Los campos de concentración franquista y la recuperación de la memoria histórica' [2004] en VII Congreso de la Asociación de Historia Contemporánea, Santiago de Compostela.
} 
Birle P y otros (eds.), Memorias urbanas en diálogo: Berlín y Buenos Aires (buenoslibros 2010)

Bogdan R y Taylor SJ, Introducción a los Métodos Cualitativos de Investigación (Paidós 1986).

Borja J, Espacio público, ciudad y ciudadanía (Electa 2001).

Borja J, Revolución urbana y derechos ciudadanos (Editorial Café de las Ciudades 2014).

Calvento M (Comp.), Relaciones Internacionales y Actores Locales: dinámicas, estrategias y políticas en el interior de la Provincia de Buenos Aires (CEIPIL 2020).

Cruz L, 'La reparación de las víctimas en el Convenio Europeo de Derechos Humanos' [2010] 12 Revista Española de Derecho Internacional 89.

Dussel E, Ética de la liberación en la edad de la globalización y de la exclusión (Trotta 2006).

Flyvbjerg B, 'Cinco malentendidos acerca de la investigación mediante los estudios de caso' [2004] REIS 63.

García Álvarez J, 'Lugares, paisajes y políticas de memoria: una lectura geográfica' [2009] Boletín de la A.G.E. 175.

Gómez Isa F (ed), El Derecho a la memoria (Giza Eskubideak 2006).

Guber R, La etnografía. Método, campo y reflexividad (Editorial Norma 2001).

Halbwachs M, La memoria colectiva (Prensas Universitarias de Zaragoza 2004 [1968]).

Harvey D, Justicia, naturaleza y geografía de la diferencia (Traficantes de sueños 2018 [1996]).

Hernández Sampieri R, Fernández Collado C y Baptista Lucio P, Metodología de la investigación (McGraw-Hill Interamericana 2006).

Herrera Flores J, La reinvención de los derechos humanos (Atrapasueños 2008).

Herrera Flores J, Los derechos humanos como productos culturales (Catarata 2005).

Horkheimer M, Teoría crítica (Amorrotu 2003 [1974]).

Huyssen A, En busca del futuro perdido. Cultura y memoria en tiempos de globalización (FCE 2001).

Jelin E, La lucha por el pasado: Cómo construimos la memoria social (Siglo Veintiuno Editores 2017).

Jelin E, Los trabajos de la memoria (IEP Instituto de Estudios Peruanos 2012).

Kuri Pineda E, 'La construcción social de la memoria en el espacio: una aproximación sociológica' [2017] 11 Revista Península 9.

Lefebvre H, El derecho a la ciudad (Capitán Swing Libros 2017 [1968]).

Lefebvre H, La producción del espacio (Capitán Swing Libros 2013 [1974]).

López Guerra L, 'El derecho a la verdad: ¿la emergencia de un nuevo derecho en la jurisprudencia del Tribunal Europeo de Derechos 
Humanos?' [2018] 22 Anuario Iberoamericano de Justicia Constitucional 11.

Marradi A, Archenti N y Piovani JI, Metodología de las ciencias sociales (Emecé Editores 2007).

Nora $\mathrm{P}$, Les lieux de mémoire (Trilce 2008).

Rodrigo J, 'Políticas de la memoria, lugares del olvido. Los campos de concentración franquista y la recuperación de la memoria histórica' [2004] en VII Congreso de la Asociación de Historia Contemporánea, Santiago de Compostela.

Schindel E, 'Memorias barriales y derecho a la ciudad: la recuperación de ex CCD como práctica de resistencia y reconstitución del tejido social' [2011] Actas del IV Seminario Internacional Políticas de la Memoria, Ampliación del campo de los derechos humanos<http://conti.derhuman.jus.gov.ar/2011/10/mesa_17/s chindel_mesa_17.pdf> acceso 29 Abril 2021.

Till K, 'Wounded cities: Memory-work and a place-based ethics of care' [2012] 31 Revista Political Geography 1.

Vasilachis De Gialdino I (Coord.), Estrategias de investigación cualitativa (Editorial Gedisa 2006)

Wieviorka A, L'ère du témoin (Plon 1998). 